\title{
Back to basics: returning to the evidence and mapping knowledge in south Asian archaeology
}

\author{
Jason D. Hawkes ${ }^{1}$ (D) Anne Casile ${ }^{2}$
}

Received: 30 November 2019 / Revised: 18 April 2020 / Accepted: 22 April 2020 / Published online: 6 May 2020

(C) The Author(s) 2020

\begin{abstract}
In this article we advocate a return to the consideration and examination of the basic building blocks of archaeological enquiry: the evidence. Reacting to a widely held perception that archaeology now understands various commonalities of human experience, we suggest that such concepts and the inevitable oscillation towards "big picture" approaches that stems from them are problematic. They engender a type of scholarship that does not always engage fully with the evidentiary bases of interpretation and that risks assuming a great deal about large parts of the world that have not been studied in as much detail as others. We explore this by looking at the South Asian context, where archaeologists are forced to contend with a number of constraints, chief among which is a relative absence of archaeological evidence. Focusing on one particular sub-region, we piece together exactly what evidence exists and consider what can (and cannot) be said from it. On one level this serves as a useful comparator for those working in other parts of the world who may not appreciate the evidentiary constraints that exist elsewhere. Yet beyond this and simple questions of analogy, we suggest that detailed consideration of an area such as the one presented here forces us to return to even more fundamental questions relating to when archaeological research becomes "interesting", "ground-breaking", and "new"; and who decides this.
\end{abstract}

Keywords Archaeology $\cdot$ Comparative approaches $\cdot$ Evidence $\cdot$ Mapping $\cdot$ South Asia $\cdot$ Theory

\section{Introduction}

Archaeology, like all academic disciplines and the knowledge systems they belong to, is not fixed. It changes. The archaeology of today (if such a singular thing exists) bears little relation to the earlier antiquarianism from which it developed. Recently, the pace of that change has sped up. We can see this methodologically and theoretically, with the development of existing perspectives and approaches, and the exploration of new ones. Methodologically, we might cite such diverse and wide-ranging avenues as: agent-based and other advanced modelling techniques (Wurzer et al. 2015), geoarchaeological

Jason D. Hawkes

hawkes.jason@gmail.com

Anne Casile

anne.casile@gmail.com

1 Department of Asia, The British Museum, London, UK

2 PALOC Joint Research Unit, IRD (French National Research Institute for Sustainable Development), Paris, France analyses (Canti and Huisman 2015; French 2003), geospatial technologies and processing techniques (Opitz and Herrmann 2018; Orengo and Petrie 2017), microbiological analyses (Margesin et al. 2017; Weiner 2010), palaeoproteomics (Hendy et al. 2018), and participatory research (McAnany and Rowe 2015) to name but a few. These approaches generate a wide range of data, big and small (and rarely complete), that form the basis of what we think we know. Interpreting those data, we benefit from the exploration of an everincreasing range of ideas, such as those surrounding agency, complexity, gender, identity, landesque capital, materiality, networks, ontologies, political ecology, power, and resilience (e.g., Ashmore 2018; Giosan et al. 2013; Håkansson and Widgren 2014; Hodos 2017; Meskell and Preucel 2008). We have also begun to look at various topics in ways that extend beyond the traditional nature versus culture dichotomy around which the humanities developed. Mention might be made of new ways of thinking about agriculture, land use, behavioral ecology and evolution (Bettinger et al. 2015; Brughmans et al. 2016; Denham et al. 2016; Garvey 2018; Håkansson and Widgren 2014; Morrison 2018), as well as archaeological practice in postcolonial contexts (Lydon and Rizvi 2016). 
Consequently, the number of themes being explored has proliferated, as archaeology (and what is deemed to fall under the umbrella of archaeology), expands inexorably to fill the intersections of the sciences, arts and humanities.

With these developments there has also emerged a sense that we have the answers to certain topics. This is expressed in a number of ways. First, we think we "know" how certain socio-cultural and economic processes and structures worked. Drawing on over a century of archaeological and ethnographic research (which itself draws on an even larger body of biological, economic, philosophical, political, and social thought), we are often tempted to fall back on the use of certain general terms such as "complexity", or even more specifically: "agriculture", "production" and "trade." These labels have become convenient blanket terms implying a set of activities that many of us no longer try to define, because we assume that we understand the mechanisms of such behaviors and associated practices in the areas where we work. Second, and on a slightly more concrete level, when we "know" that certain broad developments happened across a given unit of space or time we often infer the existence of certain associated societal and cultural systems and accompanying archaeological features within that same space and time. In thinking about Roman Gaul, for instance, we might presuppose the existence of similar processes of acculturation and urbanism, and associated archaeological remains across large areas of modern-day France. Third, and on another level entirely, many of us will be familiar with archaeology's tendency to constantly look for the next new cutting-edge topic of research. ${ }^{1}$ Implicit in this is the idea that we, as a discipline, have already tackled a growing list of topics that do not need to be revisited because we have thought our way around them, and comprehensively articulated those thoughts.

At the same time, and as a corollary of this, there is also a (perhaps inevitable) oscillation towards "big picture" approaches and comparative perspectives. ${ }^{2}$ While this does not necessarily account for the entire trajectory of archaeological research, there is undoubtedly a growing trend towards studies that seek to either place region-specific developments into a broader framework of understanding, identify commonalities of experience, or tease out deeper understandings of why differences exist. For example, we might cite studies that have

\footnotetext{
${ }^{1}$ While this is a relative indicator of good "intellectual health" and can be considered a positive dynamic, it is not unrelated to a widespread and increased drive to secure funding to ensure that academic departments and institutions continue to be economic viable. The ability to think up new ideas and secure funding in turn frequently becomes conflated with the assessment of an individual scholars' ability and worth; and project-based research becomes the dominant model and measure of "success."

${ }^{2}$ In many respects, much of the wider history of archaeological research can be characterized by a generational toing and froing between approaches and entrenched standpoints. These may be differences between empiricism and relativism, processualism and post-processualism, proponents of sociocultural evolution and cultural specificity, and so on (see Trigger 2006).
}

returned to the study of seeming universals, such as the development of complex society (Pozorski and Pozorski 2018; Renfrew and Liu 2018); the "global turn" in medieval archaeology (Pitts and Versluys 2014; Campbell 2016; Jervis 2018); or the increasing popularity of "big data" approaches to the incorporation and synthesis of the vast amounts of variation in the past to tease out and identify developmental trends (Gaillard et al. 2015; Gilbert and Doran 1994; Pielke et al. 2011; Strandberg et al. 2014).

It is not for this article to comment on the rights or wrongs of such approaches. We fully recognize the value of comparative perspectives and the exploration of commonalities of human development or experience. This stimulates ideas and questions, and building on earlier research is how research is driven - it is a process of constant critical reflection and iteration. Yet, at the same time, placing too much faith in the idea that we "know" something can have unintended consequences. Usually, these revolve around losing sight of the specifics of the archaeological contexts in which we are working. These may be the details of how archaeology operates in any given context (its historiography, how institutional frameworks and established modes of practice have been created, how they have led to questions that are asked, how they have shaped the collection and selection of data, and how they have defined wider research agendas), the nature, relative "quality" (and quantity) of the data that exist (which is dependent on the kinds of data that have been collected, how they have been collected, and the resolution with which they can be dated), or an awareness of what is not investigated and remains invisible.

In "knowing" that certain developments to have taken place, there is a danger that we might assume the archaeological data will play out in a particular way before (or sometimes without) looking at it properly. For example, studies of the European Neolithic frequently made recourse to models of demic diffusion to chart the spread of farming across Europe (Ammerman and Cavali-Sforza 1971). Implicit was the notion that demographics, agricultural practices, and patterns of settlements were the same in areas where farming was deemed to have spread. An extension of this idea was to then assume the existence of settled villages characterized by a particular suite of material remains indicating a particular set of activities and practices without necessarily having the data to (fully) support these presuppositions. Indeed, it was only relatively recently that scholarship became attuned to the great deal of variation that existed in terms of farming and settlement (e.g. Bocquet-Appel et al. 2009). In a different sense, because we might understand the mechanisms of "trade" and "exchange" with reference to a number of interpretive frameworks (e.g. Polanyi 1944; Malinowski 1922; Mauss 1970), there is 
a danger that when we investigate a theme that involves these practices we presuppose the way they functioned.

We accept that these might be dismissed as imagined concerns. Yet, the perceived risk of making such uncritical assumptions grows when we consider it in relation to broad inter-regional and comparative studies. These can easily assume similar standards of data quality and comparability across different areas. In doing so, they may not necessarily consider the variable recovery strategies that have been employed to generate the data being compared, or differential archaeological visibilities that might affect and undermine the comparisons that are made. Similar concerns surround recourse to secondary sources from other contexts, which themselves may be the products of different schools of thought and practice and may thus be plagued by similar issues of (in)compatibility. It is with these thoughts in mind that we suggest there is perhaps a need to ask ourselves: what is the evidence that we have, and, if we are being completely honest with ourselves, what can it tell us? In simple terms: what can and can't we do with the available data? In doing so, we can guard against "alternative facts" creeping into research and at the same time refine our sense of what needs to be done with future work on any given topic or in any given area.

Here, we explore this issue with reference to an example from the South Asian archaeological record, where distinct (though not necessarily unique) dynamics are at play. In particular, there are large geographical areas and periods of time that have rarely, if ever, been subjected to archaeological enquiry. We might cite, for instance, a comparatively disproportionate focus on the Indus civilization in studies of the third millennium BCE (e.g., Kenoyer 1998; Possehl 2002; Shinde 2016; Wright 2010), or, at the other end of the chronological spectrum, a relative absence of any sort of an archaeology of later historical periods, particularly the medieval (Hawkes 2014). The reasons for this are frequently related to modern political ideologies (see Chakrabarti 1998, 2003). There are also a series of methodological constraints, with various bureaucratic, infrastructural, and legislative factors affecting both the quality and quantity of archaeological data that have been and continue to be generated. This is a situation that poses particular interpretational challenges, not only for those working in South Asia, but also those working elsewhere that might seek to incorporate the evidence from South Asia into comparative frameworks. At a certain point we must contend with basic (and all too familiar) questions of analogy. To what extent can the archaeology of one region be compared with that of another without full consideration of their limitations, and is it possible to simply apply theoretical ideas borne from one context in the study of another? Following an introduction to these issues, we will spell out exactly what sort of evidence we have and consider the shortcomings and biases that exist within it and the ways these might limit and constrain what we can do. We then consider the sorts of approaches that we can take with the evidence available, and which we have mapped.
In doing so, the wider ramifications of returning to the evidence will become clear. These force us to reflect on a number of things that extend beyond archaeology in South Asia - whether there is, perhaps, an argument to be made for going back to basics, returning to the evidence in archaeology generally and, by mapping it, seeing what it can and cannot tell us. On a wider level, we suggest that there is perhaps a need to look closely at questions relating to when archaeological research becomes "interesting", "ground-breaking", and "new", and who decides this.

\section{Background}

Within South Asia, the mid-first millennium CE (c. third to seventh century) appears to have been a particularly transformative time. We see the appearance of new dynasties and kingdoms in epigraphic records across South Asia (Agrawal 1989; Raychaudhuri 1923; Singh 1994). These are often considered with reference to rule of the Guptas - a particularly powerful dynasty who ruled across North India, and under whose rule "classical" Indian artistic and literary forms took shape (Harle 1974; Singh 2003; Stein 1998). The appearance of these kingdoms was connected to the growth and spread of new "Hindu" temple institutions (Gupta 1974), which were themselves linked to new sects of Shaivism and Vaishnavism (Bakker 1997; Bisschop 2010; Stein 1998). Temple institutions and communities of brahmins (those belonging to the priestly caste) received royal patronage and became increasingly embedded in local social and economic and political networks through the transference or formalization of land ownership rights (Bakker 2010; Nath 2001; Singh 1994). These new relationships were embodied in a series of inscriptions, written in courtly Sanskrit and recording royal grants of land, that spread as both a practice and form of material culture throughout South Asia from the Gupta empire (Fleet 1888; Hawkes and Abbas 2016; Mirashi 1963). Together, these features point to the development of what is deemed to be new social formations and changes in patterns of urbanism, which may also have been related to the realignment of Indian Ocean, inter-regional, and local trade networks (Kosambi 1955; Sharma 1965). These changes set the trajectory of continued social, cultural, economic, and political developments up to at least the thirteenth century. ${ }^{3}$

\footnotetext{
${ }^{3}$ The beginning of the thirteenth century represents a major turning point in the historiography of change in society of South Asia. This is largely due to the establishment of the Delhi Sultanate in 1206 CE (Wink 2002). As such, the idea that society changed due to Muslim invasions and their political and religious ramifications have dominated narratives of what has come to be termed the "late medieval" period. Ideas of political and religious changes defining periodization can be traced back to Mill (1817). For discussion, see Ali (2012).
} 
The archaeological study of this period is a complex matter. In fact, it tends not to be examined archaeologically at all. Instead, it is studied within the fields of textual history, literature, religion, and the history of art through the examination of a wide range of textual and artistic sources. ${ }^{4}$ Within those disciplines, many of the developments that are perceived to have taken place tend to be understood with reference to wider social and economic theories (themselves received from wider international scholarship), such as feudalism (Jha 1993; Sharma 1965), state formation (Kulke 1982, 1993; Stein 1980), and sociocultural evolution (Sharma 1983). ${ }^{5}$ While the overall thrust of enquiry, the prism through which the past is understood, tends to be one of societal change. The period is seen and defined as a pivotal moment, either as a Golden Age when an indigenous Hindu culture reached its zenith (e.g., Eraly 2011), or as a period that marks the transition from an earlier ancient period to a later medieval one (Chattopadhyaya 1994). Within this context, archaeological research has tended to focus on periods of time that preceded these developments. ${ }^{6}$

That is not to say, however, that there is no archaeological evidence for the mid- to late-first millennium CE in South Asia. Since the early nineteenth century, excavations at large settlement sites have revealed a great deal of evidence that can be dated to the period. This is mostly in the form of ceramics, associated craft products and, to a lesser extent, coins. Excavations have also been carried out at temples and other religious sites. These have yielded architectural and carved remains, both epigraphic and sculptural. Additional stray finds, such as displaced sculptures and coins, continue to be unearthed in the field and private collections. However, because the period is not the main focus of archaeological research, few of these excavations have been carried out with the aim of investigating the period itself (Hawkes 2014). Rather, in the case of settlement archaeology at least, they are the almost accidental product of excavations that have been carried out to uncover the underlying earlier (more "interesting") layers. The exceptions to this trend are religious monuments, which are excavated in reasonably large numbers. Yet, the carved architectural remains that result from these digs tend to be incorporated not into archaeological research, but rather into textual and art-historical studies where they are deemed to be more appropriately situated (Hawkes

\footnotetext{
$\overline{4}$ These include inscriptions (the majority for this period being copper-plate inscriptions recording land charters) and Sanskrit and Pali documents found across the subcontinent as well as sculptures and architectural remains that are frequently interpreted with reference to religious texts.

${ }^{5}$ This is contra approaches to other (earlier) periods that are increasingly taking more political ecological approaches (e.g., Bauer 2018).

6 Specifically, an "early historic" period defined by the appearance of coins, writing, and urbanism that stretched from approximately the sixth century $\mathrm{BCE}$ to the early centuries CE; an Iron Age or "megalithic" period that extends from at least the late-second to the mid- to late-first millennium BCE; the Chalcolithic, defined by the study of the Indus civilization and other contemporary cultures of the fourth to second millennia BCE; and beyond (to at least one million years ago).
}

2014; Singh 2011). Excavated remains become empirical evidence that are used to corroborate wider historical ideas, while architectural and sculptural remains are placed within iconographic and stylistic frameworks.

That this is the case is well known within scholarship on South Asia. It is due to various issues such as the interests of colonial scholarship and post-colonial reactions to them (Guha-Thakurta 2004; Singh 2004; Thapar et al. 1969); the dominance of culture-history approaches (Johansen 2003); the concept and problematization of the "medieval" in India (Ali 2012; Hawkes 2014); the relationships between archaeology, texts, and art (Ray and Sinopoli 2004); and the role of archaeology within professional, governmental, and academic circles (Chakrabarti 1998, 2003). Stemming from an awareness of these issues there is also a growing realization of the necessity of investing the study of this period with a more archaeological approach. A small but growing number of projects are starting to tackle this problem face on. Here, one might cite work ongoing excavations at Mahasthangarh (Salles 2015), landscape surveys in Bangladesh (Sen 2015), renewed excavations of religious and urban sites dating to the mid-first millennium CE in Central India (Kennet et al. 2020; Sontakke et al. 2016), and our own project's work looking at the landscape contexts of inscriptions (Hawkes and Abbas 2016). Indeed, with so much potential for truly foundational research, these are particularly exciting times to be involved in the archaeology of later historical periods in South Asia. Yet, it is important to remember that when it comes to looking at the archaeology of at least half a millennium of human history across an area more than half the size of Europe, this is the intellectual and methodological framework within which we are operating, and we need to be clear about what this means both methodologically and theoretically. ${ }^{7}$

This relative absence of archaeology brings with it a number of challenges, the first of which is the question of what we as archaeologists chose to look at. Like a metaphorical child in a confectioner's, there is a bewildering array of choices. Equally convincing arguments for studying any number of topics can easily be made. However, rather than looking towards wider archaeological literature and studies of other contexts that might have tackled similar methodological or conceptual problems to stimulate ideas for possible directions of further research, what tends to happen is that the investigations that are carried out tend to ask the same familiar questions that have already been defined within textual scholarship on South Asia. For example, political dynasties continue to dominate the way that the past and historical change are understood and defined. So, when it comes to decisions about which sites are "important" and worthy of excavation, these

\footnotetext{
${ }^{7}$ It is worth pointing out here that many of the same concerns can be levelled at the study of the later medieval (or Middle Period) and early modern periods, too, which are subject to even less archaeological study.
} 
choices are often made and justified with reference to its historically attested connection with that dynasty. This frame of reference also dictates how archaeological remains are dated, defined, and discussed. We have, for instance, the notion of "Gupta period" pottery, as if people in the past changed the way that they made ceramics, expressed their cultural identity, and engaged in certain social practices in accordance with a change of ruler. Our conceptions of "culture" tend to be based on the literary and artistic outputs of religious and political elites. At the same time, archaeological research on the period continues to be preoccupied by the questions received from historical scholarship, such as: "was society feudal?" and "what was the relationship between Hindu temple institutions and kings?" These questions are further explored with reference to either established textual-historical ways of thinking about the past (which themselves have drawn heavily on wider social scientific theories). ${ }^{8}$ None of these approaches are necessarily incorrect, and we certainly do not wish to prescribe what should be done. However, if such approaches are taken it behooves practitioners, academics, and institutions to accept that they are underutilizing the potential of the evidence and selling short the potential benefit of archaeology.

The second issue is as much a methodological challenge as it is a conceptual problem. With so little archaeological work having been done, our knowledge and understanding of the evidence from this and later periods is limited. In simple terms, we know of far fewer archaeological sites that date to this period than we do for those that can be dated to earlier periods (Hawkes 2014). We also have only the most rudimentary understanding of the material culture from those sites. There is, for instance, no established pottery typology for this entire mid-first millennium period at a local or regional scale. ${ }^{9}$ In part, this is due to the lack of archaeological research on this period. It is also due to certain features of professional and academic practice in the field of South Asian archaeology. Site reports (for sites from any period) are rarely published, while notices of the discovery or excavation of sites are often very brief. ${ }^{10}$ Nor is there a single resource or established mechanism for reporting and disseminating the results of surveys

\footnotetext{
${ }^{8}$ Indeed, the irony here is that many of these questions first became articulated in historical scholarship following an awareness, in the mid to late twentieth century of the value of wider social scientific research including the range of new perspectives that archaeology could bring (e.g., Sharma 1983).

${ }^{9}$ Pottery reports that have attempted to classify pottery found during individual excavations exist (e.g., Kennet et al. 2020; Nath 2016). Yet methods of pottery analyses vary and are rarely published in detail, making it difficult to compare remains either as they appear in print, or physically in assemblages (when access can be obtained). As such there is no established typology of "Gupta period" pottery or any other frequently cited type or ware from later historical periods. For further discussion, see Lefrancq et al. (2019).

${ }^{10}$ Only approximately 14\% of sites excavated between 1947 and 1995 have been published (for details see Chakrabarti 2003), and notices of the discovery and/or excavation of sites in the annual reports published by the Archaeological Survey of India typically range in length from a single line to two pages of text.
}

and excavations within any one country let alone across the whole of South Asia. In part, this is a consequence of multiple stakeholders being involved in archaeological practice and the fact that their findings are published in different languages. India alone is home to 780 official languages, and archaeological reports frequently appear in Assamese, Bengali, English, Gujarati, Hindi, Kannada, Maithili, Malayalam, Marathi, Odia, Punjabi, Tamil, Telugu, and Urdu. This has led to the creation of knowledge silos in which the information that we do have about this period (and others) languishes unknown and unstudied by others operating in different geographic areas and working in different languages. Together, these factors mean that when archaeologists do try to inject a more material culture-based approach into their examination of the period, we simply do not have an existing framework of archaeological evidence in which to ground our theoretical perspectives, interpretations, and conclusions.

The net result of this is that our archaeological understanding ends up being somewhat hypothetical and, without comparison to wider archaeological questions, is in danger of becoming increasingly insular. We find ourselves necessarily having to make recourse to a series of ideas culture and society-about settlement, economy, and what things must have meant to people in the past and how societies functioned. Interpretations about any and all of these things are made on the basis of what we infer to have been the case. In other words, we find ourselves resorting to wider social theories and falling back on heuristic devices and a set of assumptions about what must have been the case rather than being able to access and see how all of these things actually worked in what is essentially a unique archaeological context that has yet to be properly investigated. This is rarely, if ever, made explicit. Recognizing the discomfort of this situation, we again return to the perceived need of going back to basics and defining exactly what we know and what we can actually say based on the evidence that we have.

\section{What has been done}

Addressing this, we have focused our attention on one particular region-Vidarbha in Central India - in order to establish exactly what archaeological evidence exists from within it. The premise here is that it is only when we take stock of the existing evidence that we are able to assess its quality (according to any number of criteria) and establish its applicability. In other words, we must assess whether it can be used in the way(s) we would like to be able to use it, and if it cannot be used in those ways, identify the factors that constrain its use and applicability. This work then has a clear benefit in establishing the starting point for research in that region, while equally suggesting that it presents a useful approach and 
framework for also getting to grips with the archaeology of other areas.

Vidarbha measures approximately $100,000 \mathrm{~km}^{2}$ and is located in the far northeast of the modern state of Maharashtra, India (Fig. 1). This region represents a good laboratory within which to test these ideas for a number of reasons. First, it represents a coherent region both geographically and historically. Geographically, it is defined by its topography and hydrology, displaying landscapes rich in fertile lands, rivers, minerals, and areas of forested hills. Part of it falls into the Deccan plateau. It is bounded to the north and east by Satpura range (Gawilgarh, Garamsur, and Mahadeo hills), to the southeast by hills of Bastar, and to the west and southwest by hills of the Ajanta range. Most of the region belong to the
Wardha-Wainganga Rivers watershed of the Godavari basin, while its western plains are drained by the Penganga River flowing into the Tapi basin (Fig. 2). Historically, the region was the known core territory of the eastern Vakatakas - a dynasty contemporary to and neighboring the Guptas, and who were one of the first to adopt the new practice of landgrants in the fifth century CE (Bakker 2010; Hawkes and Abbas 2016). Archaeological sites relating to this period include find spots of these landgrant inscriptions, a number of known settlements and temples, as well as a number of earlier sites that enable us to place the data from the period into a broader chronological context (e.g., Sawant 2012).

To establish a complete picture of the existing archaeological evidence from this region, we carried out a comprehensive

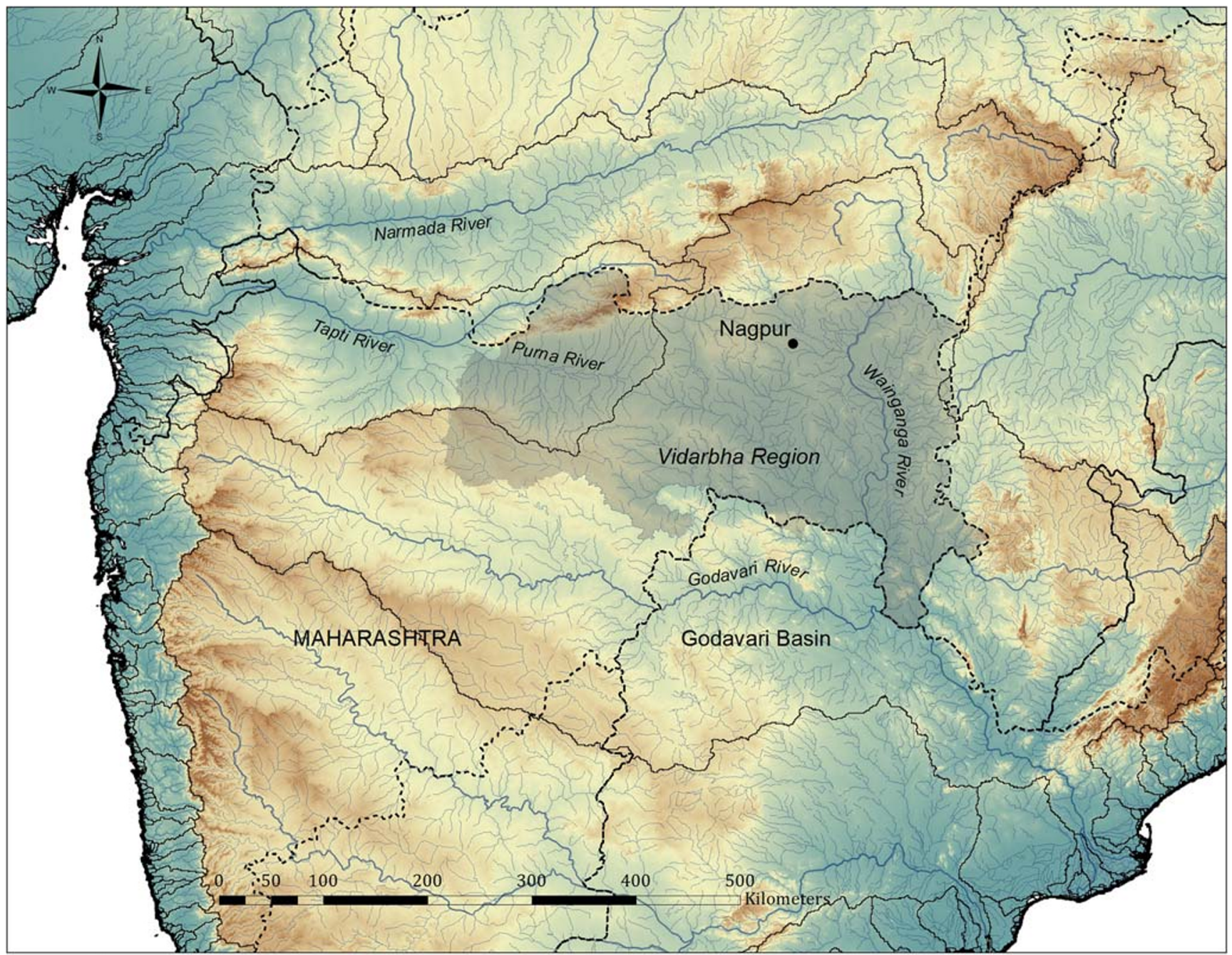

\section{Legend}

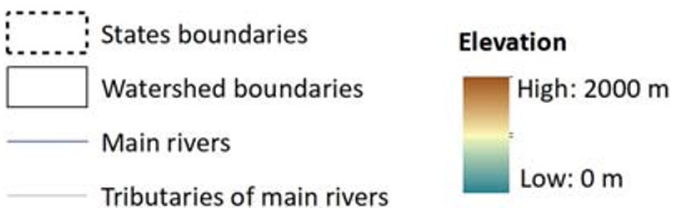

Fig. 1 Map illustrating the location and of the Vidarbha region in relation to Peninsular India 

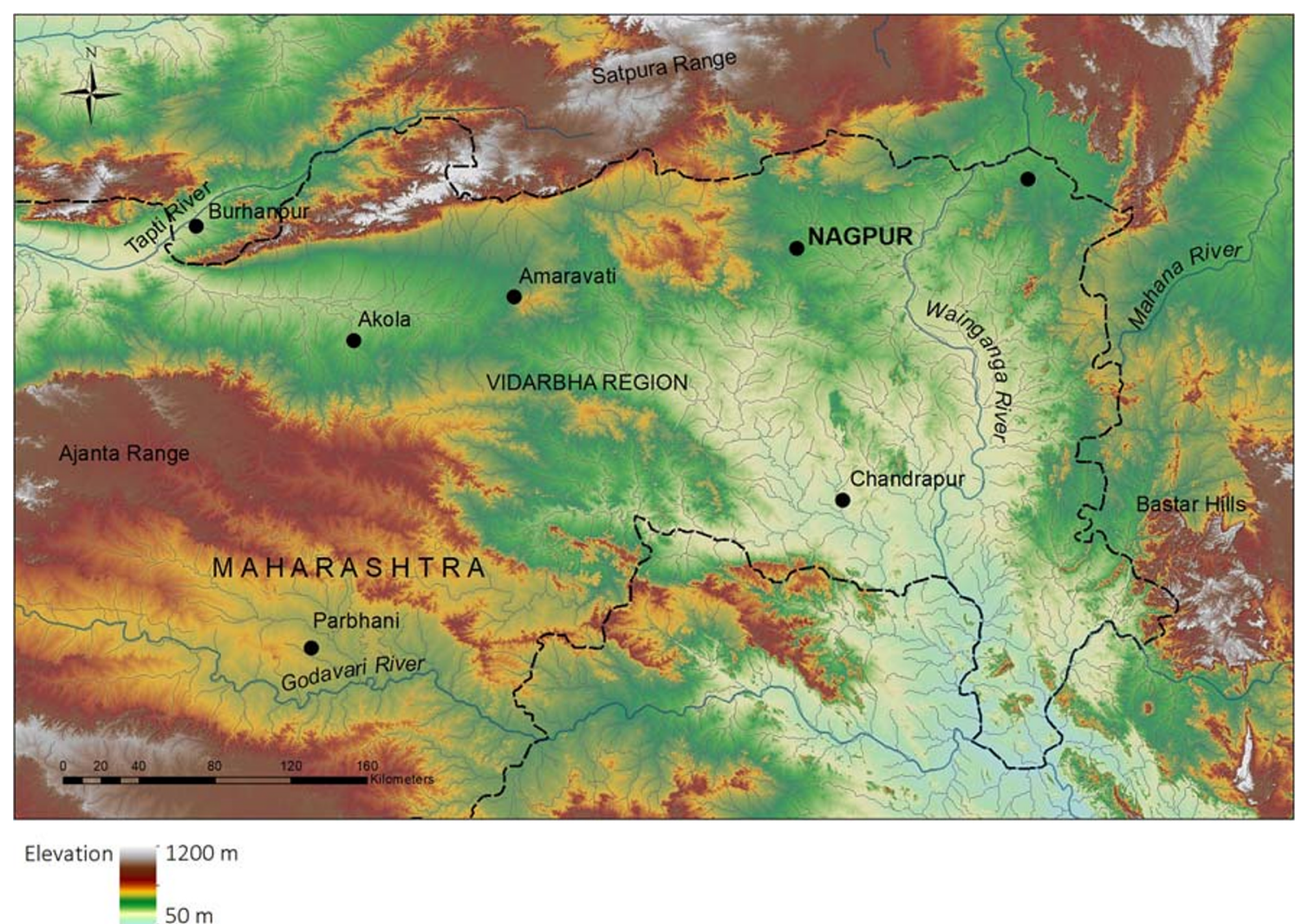

Fig. 2 Map illustrating the main geographical features that define the Vidarbha region

survey of the published and unpublished literature pertaining to this area. This included both primary and secondary sources and comprised all reports and monographs published by the Archaeological Survey of India; the bulletins, newsletters, communiqués, $\mathrm{PhD}$ theses, and other research outputs of research Universities who have been active in the area (notably the Deccan College and Nagpur University); the outputs of local antiquarian societies and individuals; as well as references to sites in the region in secondary sources. In total, 525 individual sources and 37 journal runs written in English, Hindu, and Marathi were consulted. This resulted in the compilation of a record of 1200 archaeological sites (broadly construed) in the region that date from the Iron Age or "Megalithic" period (c. first millennium BCE), to the late medieval period (c. early second millennium $\mathrm{CE}$ ).

Once a site had been identified in the literature, we recorded all of the published information relating to it. The resulting record, then, provides an accurate reflection of the data as it exists in scholarship. The only exceptions to this were sites that had been excavated (by far and away the minority), for which we summarized the published evidence for ease of data entry and comparison. In choosing what data to record, we were led by the categories of information the reports themselves contained. This included locational information about sites (written descriptions of where sites are, their geographical coordinates, and an assessment as to the accuracy of that location); their recorded date; and the "type" of site. Sites tend to be categorized in the literature with reference to only seven or eight repeating classes: settlements, temples, stupas (a class of Buddhist monument), caves, megaliths, sculptures, inscriptions, and coins. ${ }^{11}$ To facilitate ease of comparison and interrogation of the data, we have attempted to standardize these as much as possible and impose a classificatory hierarchy across all site "types." Thus, just as "settlements" might be imagined to include a great deal of variation (which could then be classified as sub-types), we judged "temples" and "stupas" to be sub-types of a broader class that might best be termed "religious sites." These site types then defined how they were recorded in our record. Various site-specific details about each type of site (e.g., its size, physical and archaeological features, descriptions, lists of artifacts found within them or that define them) were also recorded as they appear in the literature.

Recognizing that accounts of archaeological remains are not the only things that enable us to assess the relative quality of the data, we also recorded information about how each site had been discovered, investigated, and recorded. This included details concerning the name and institutional affiliation of the person (or persons) who first reported and documented the

\footnotetext{
${ }^{11}$ There are a small number of additional types of sites that can be added to this list, such as forts, dams, and step wells. However, they are so few that they are included in our record as "other" (Hawkes et al. 2020).
} 
Fig. 3 Chart illustrating the number of archaeological sites (in ordinates) in Vidarbha in relation to site type and period

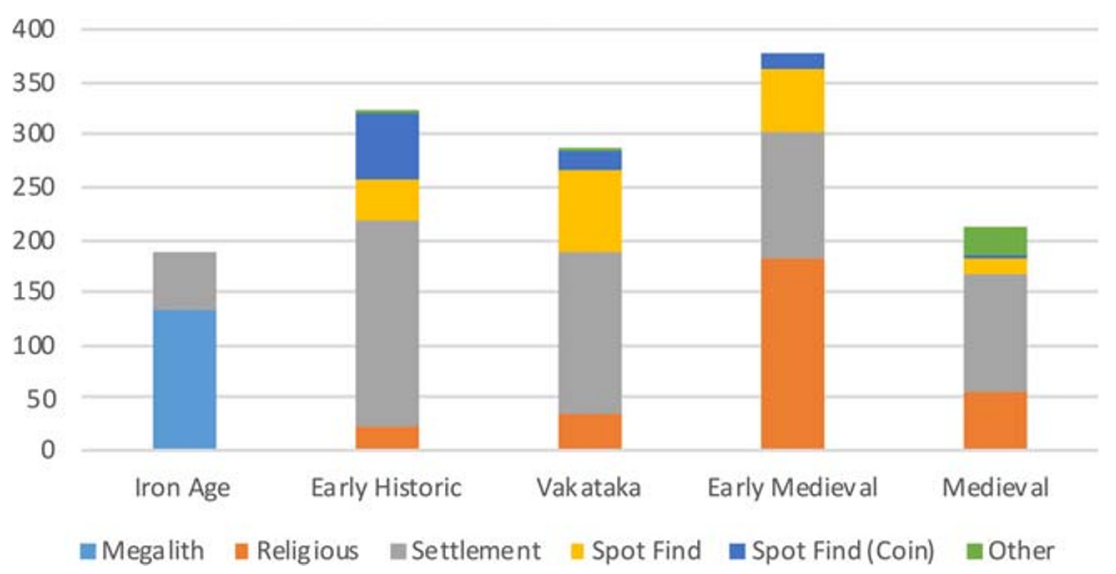

site; those who directed any subsequent phases of work; why that particular survey or excavation was carried out; and the methods used. Of course, not every report contains all this information. Indeed, most do not. By compiling as complete a record as possible of all of the information that has been reported, it was thus also possible to see what has not.

Once gathered, all the information was recorded in a flat file database to facilitate the interrogation and analysis of the data, the results of which are discussed below. However, the publication of such a large dataset presents some problems, even if it is presented as an appendix at the end of an article such as this one. We have thus made this record available online in table form (.csv format), together with the related bibliography (in .rtf format), both of which are open-access and can be freely downloaded and interrogated (Hawkes et al. 2020). Such is the nature of information silos we recognize there is a chance that the dataset is not complete. However, we do not think that this undermines it or any of the observations that can be made on the basis of its examination. The pace of research that it will inevitably be out of date in due course. We hope that making this record openly accessible will enable it to be constantly updated (individually or collectively) and facilitate further scholarship.

\section{Consideration of the data}

\subsection{What sites exist?}

Once compiled, the regional data were interrogated to assess exactly what archaeological evidence exists, and its limitations. The first step was to plot the quantities of different categories of sites (as defined above) over time, according to the broad chronological periods of time recorded in the literature (Fig. 3). ${ }^{12}$ This would appear to indicate

\footnotetext{
12 There are specific concerns with the way archaeological sites and remains are dated and/or attributed to particular periods, not to mention the bases on which periods are defined in wider scholarship on South Asia. The ways in which these impact our engagement with and interpretation of the existing data is discussed in greater detail below.
}

that there was a sharp increase in the number of sites during the transition from the Iron Age to the early historic period and that most of the sites in the area date to the early medieval period. Within each period we can also see different proportions of site types. The number of settlements, for instance, increases from the Iron Age to the early historic, and then slowly declines in each successive period. In scholarship on South Asia, the temptation has been to use quantities of sites such as these as reflecting wider trends without adequate consideration of the reasons behind their variation. So, for instance, the numbers of settlements in each period might normally be taken as a measure of how "settled" an area was and how that changed over time, often in relation to wider conceptions of the development and spread of urbanism. Or the numbers of religious sites might be attributed to different religious sects, and their quantity taken as a rudimentary indicator of how societally embedded that religious institution was.

However, the data thus displayed cannot, by themselves, be understood as an accurate reflection of any sort of past reality, or at least not so simplistically. The results of each individual survey or excavation add to this overall picture, which is, by definition then, highly contingent on those results. This can be seen clearly when we consider the results of individual investigations. For instance, if we remove records of sites recorded during Lacey's survey of the Ramtek area in 2010-2012 (Lacey 2016), then the quantities of known site types in each period change considerably (Fig. 4). Indeed, this survey alone was responsible for more than doubling the number of known medieval sites and remains in the region. While the overall proportions of sites by period (other than the medieval) do not alter too much, we can see that without the data produced by this one survey the perceivable changes in the quantities of settlements over time are much more pronounced. The incorporation, then, of the results of individual investigations can have a significant impact on how we perceive the archaeology of the region, and by extension what we can say about the past. 
Fig. 4 Chart illustrating the number of archaeological sites in Vidarbha in relation to site type and period without Lacey's (2012) survey data

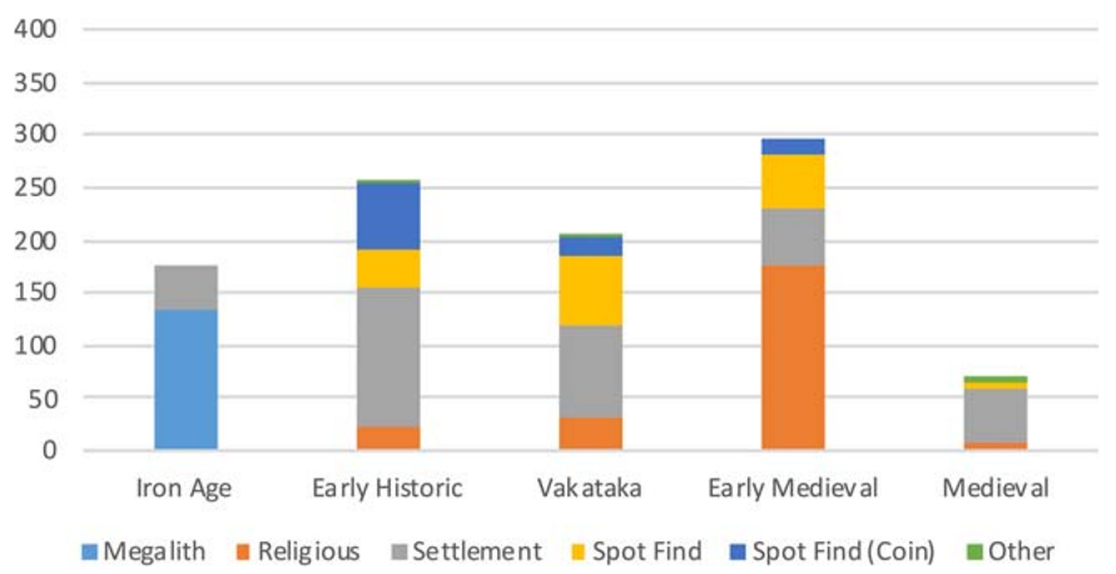

\subsection{Aims, methods and modes of examination}

More fundamentally, we cannot take the quantity of sites being in any way representative of the past without having some idea of how much of the region has been examined, the ways it has been examined, by whom, and why - the biases of previous research. We can identify some of these by considering the aims and methods of past investigations. If we assume (for the purpose of investigation) that the sites recorded in reports of excavations and explorations were documented during the same season of fieldwork, we can identity 128 individual campaigns of fieldwork carried out by at least 71 different individuals and teams over the last 130 years that resulted in the discovery of archaeological sites and remains. ${ }^{13}$ Each of these were initiated for different reasons, and all had different aims and objectives. Thinking first about the motivations that lay behind these various programmes of work, we see seven investigations being carried out explicitly for rescue and research (Banerji 2000: 52-53; Joshi 1992: 59, Joshi, 1993a, b: 82, 83-84; Mahaptra 1994: 58-59, Mahaptra 1995: 43-45; Menon 2002: 67-69), but in the vast majority of instances (the remaining 121 investigations) there is no record of why programmes of fieldwork were initiated at all. In terms of their aims and objectives, the situation is slightly better. We find that seventeen surveys were carried out to investigate particular geographical areas. These include the rescue surveys mentioned above that focused on planned submergence areas prior to dam construction, as well as (presumably researchoriented) studies looking at discrete local areas (Beglar 1878; Borkar 1986, Borkar 2009; Chitale 1987, 1988; Cunningham 1879; Dixit 1954; Shete 2011-2012; Sontakke 2014; Vaidya 2014). At the same time, eleven surveys were undertaken to investigate a particular time period (Abbas 2016; Deshpande

\footnotetext{
13 To clarify, sites that were discovered by chance outside the remit of archaeological investigations are not included in this number. In addition, other archaeological surveys that did not result in the discovery of new material are also known to have been carried out (e.g., Bhaisare 2012), and so are also not included in this number. For further details, see Hawkes et al. (2020).
}

1975; Joshi, 1993a, b; Joshi and Sharma 2000; Lacey 2016; Misra 2004; Mitra 1983; Shete 2011-2012; Sontakke 2014; Thapar 1979a: 21, Thapar 1979b: 36, Thapar 1980a: 39, Thapar 1980b: 39; Vaidya 2014); and three were carried out to investigate specific types of sites (Banerji 2000; Deshpande 1975; Kale 1999) (Fig. 5).

However, not all of these reports are clear about their geographic area of enquiry, and an astonishing 104 surveys do not record their aims and objectives at all. In the absence of records of what individual investigators were doing, their aims can be inferred by looking at the results of surveys and excavations. Doing so reveals clear patterns in the types of sites and chronological periods that have been targeted. Looking first at surveys (Table 1), we can see that for investigations geared towards (or perhaps simply more sensitive to) recording settlement remains they tended to favor sites dating to the early historic and Vakataka periods, while those seeming to investigate religious sites focused on early medieval remains. Equally, when considered in terms of possible periods of interests, studies of the Iron Age have clearly focused on megaliths, studies on the early historic and Vakataka periods on settlements (the latter with a slight additional interest in religious sites), and for studies of the early medieval temples and spot finds (usually inscriptions and sculptures) appear to have been the motivating factors. The later medieval period has hardly been of interest at all.

If we look at excavations and consider site types and their dates as indicators of the aims of the investigators, we can identify some additional patterns (Fig. 6). Regionally, Iron Age sites (both settlements and megaliths) have been the main foci of excavations - the sites deemed most worthy of full archaeological investigation - while settlements and (increasingly over time) religious sites dating to the early historic and Vakataka periods are the next most common foci of enquiry.

On one level, these biases can be explained and understood with reference to the research interests of individual scholars, which in turn point to wider trends in 


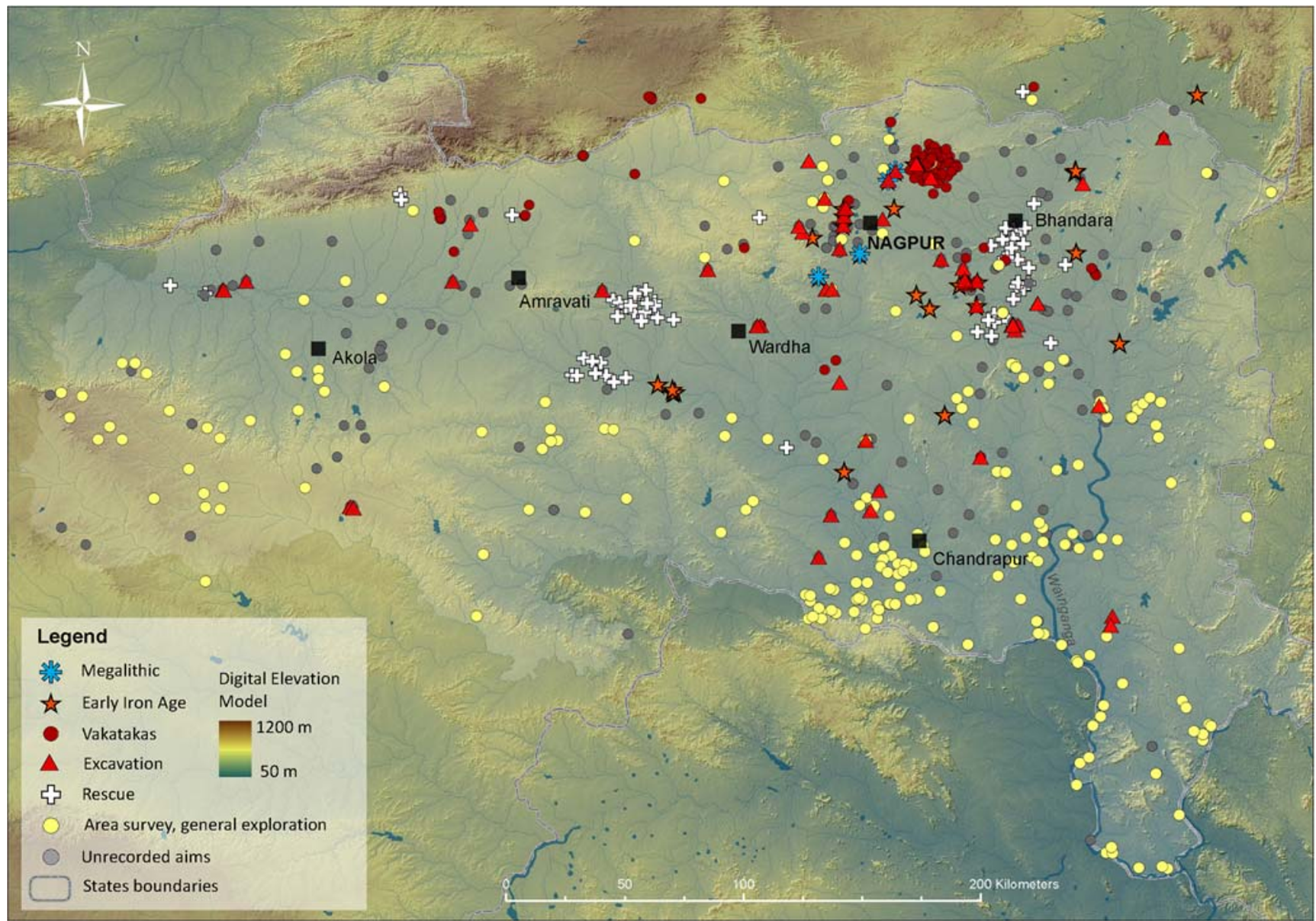

Fig. 5 Map illustrating the known archaeological sites in the Vidarbha region, displayed according to the stated aims of investigation that resulted in their initial discovery

the scholarship. For Indeed, if we consider the aims of the individual investigators (as much as we can reconstruct them) in relation to the decades in which they took place, we can identify some interesting trends (Fig. 7). We see that until the 1950's, reports were mostly concerned with remains dating to the early medieval period. In subsequent decades, their popularity was overtaken by that of early historic remains. This may not necessarily reflect a change in the focus of research. A number of factors might explain this change, for instance the obtrusive nature of later remains that would have made them more apparent to surveyors in earlier decades before the introduction of more systematic survey methods.

This might also be related to the fact that we can also see a change in the type of sites that were recorded in each decade of research, with settlements and religious sites as opposed to isolated spot finds accounting for an ever-increasing proportion of sites. However, we can also see that in each decade, religious sites and spot
Table 1 Table illustrating the number of archaeological investigations by site type and inferred period of interest

\begin{tabular}{lcllll}
\hline Site Type & Iron Age & Early Historic & Vakataka & Early Medieval & Late Medieval \\
\hline Settlement & 18 & 39 & 34 & 17 & 18 \\
Religious & 0 & 13 & 19 & 29 & 7 \\
Megalith & 31 & 0 & 0 & 0 & 0 \\
Spot Find & 0 & 5 & 9 & 18 & 2 \\
Coin & 0 & 2 & 3 & 0 & 0 \\
Other & 1 & 1 & 2 & 0 & 2 \\
\hline
\end{tabular}


Fig. 6 Chart illustrating the quantities of different types of sites dating to different periods that have been excavated in the Vidarbha region

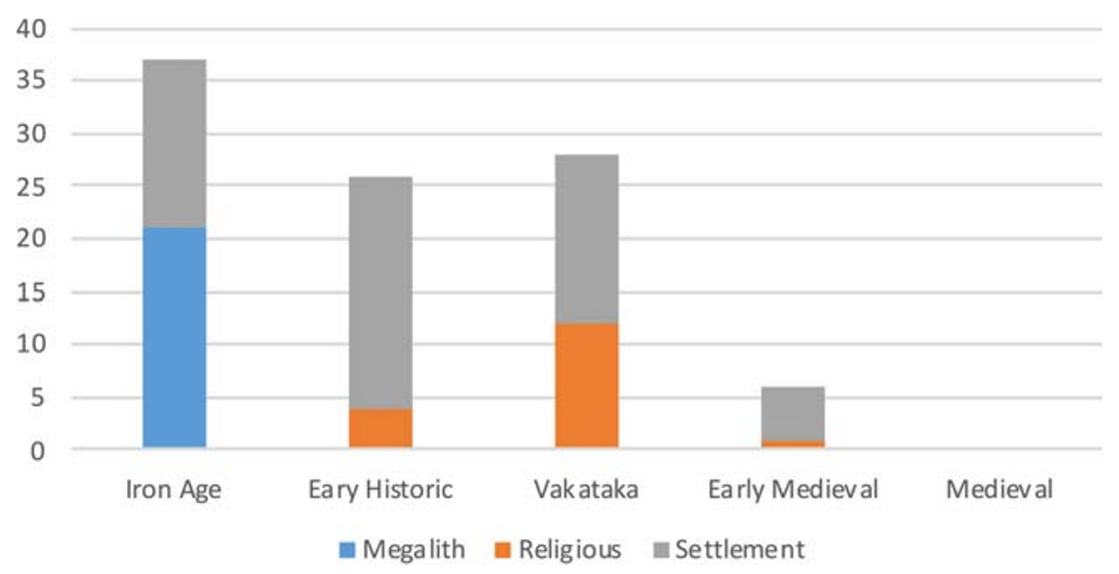

finds form a greater proportion of sites dating to later periods than they do for earlier periods. This can be understood as a direct result of the tendency to favor art historical and epigraphic remains in the study of later periods (as discussed above).

We could probe the data more deeply to reconstruct even more of the possible biases of previous research. Examination of what researchers have focused on might allow us to trace the impact of individual scholarship on the accrual of archaeological data. This would certainly be of value for studies of the history of scholarship. However, the further we explore the data in this regard, the more assumptions we have to make in interpreting any correlations that we might find. Plus, as far as reconstructing intentional bias is concerned, this would only confirm what we already know - that there was bias. A much more important concern is that because there is so much missing information about the biases of previous research it becomes very difficult to reconstruct their effects on the quality and quantity of the archaeological evidence that we have. For example, without knowing exactly which areas were examined and which were not, and exactly which sites were recorded within any given area and which were not, there will always be large questions surrounding the representativeness of the existing evidence.

Existing reports are equally vague about the methods that were used to recover and record sites and remains. This too affects the representativeness, comparability and "quality" of that data. We all know that various factors such as the location and scale of excavations have a bearing on the extent to which the resulting information can be used to reconstruct the activities that took place at a site. Similarly, the methods of excavation (whether they are context- or feature-based, dug only with reference to vertical stratigraphy and/or horizontal plans, whether and if so what sample strategies are employed, and how all of these activities and the data they produced were recorded; why those methods were used; and exactly who was involved in excavation) also have a bearing on the interpretation of the data we get from those excavations. ${ }^{14}$ Despite this, published excavation reports from this area rarely discuss the methods that have been used and the decision-making processes involved. Instead, we have to infer what we can from the plans and section drawings that are presented in print. However, only four excavations at three sites in the entire region have been published as site reports (Deo and Dhavalikar 1967-68; Deo and Joshi 1972; Nath 1998, 2016). In the majority of instances, results are instead brutally summarized in notices of preliminary findings or short articlelength reports that contain little information about these factors. That said, from the information we do have at our disposal, we can fairly safely presume that most excavations were small-scale, with trenches dug in undetermined locations, using a system first laid down by Mortimer Wheeler (Wheeler 1954) consisting of box grids separated by narrow baulks to facilitate stratigraphic recording. More recent excavations have incorporated a system combining "digs" (i.e., spits) and "lots" (i.e., individual units or contexts) that appears to have been borrowed from strategies employed in field missions co-directed by North American colleagues over the last twenty years or so. This method is increasingly being taught as the (single) standard universal method of excavation in the Institute of Archaeology under the aegis of the Archaeological Survey of India. Aside from the various merits of different excavation strategies, the point here is that because details of those methods are rarely provided, it is difficult to know how

\footnotetext{
${ }^{14}$ In this connection, we should mention that in South Asia it is common practice to employ locally hired village laborers to carry out the majority of the digging during archaeological excavations, while at the same time, postgraduate students (with variable field experience, and who may or may not have completed an undergraduate degree in archaeology) are frequently employed as trench supervisors. While not questioning the competence or enthusiasm of anyone involved, for those who are more familiar with excavations being carried out by those with many years of full-time professional experience, this raises a number of questions as to the ability of those engaged in excavation to: (a) recognize subtle differences in the color and texture of soil matrix indicating discrete archaeological deposits, (b) understand the taphonomic processes involved in the formation of deposits being encountered during excavation, and (c) accurately record all of the data that may results from those excavations.
} 
150

1830's - 1940's

100

50

Iron Age Early Historic Vakataka Early Medieval Medieval

150

1960 's

100

50

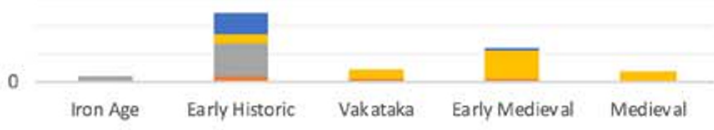

150

1980's

100

50

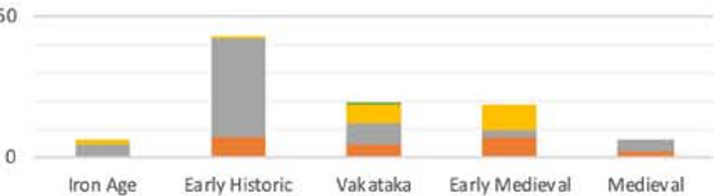

200

2000's

150

100

50

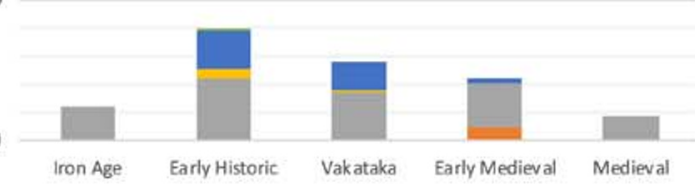

150

1950's

100

50

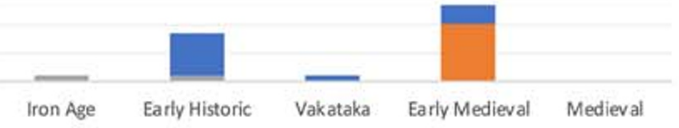

150

100

50

0

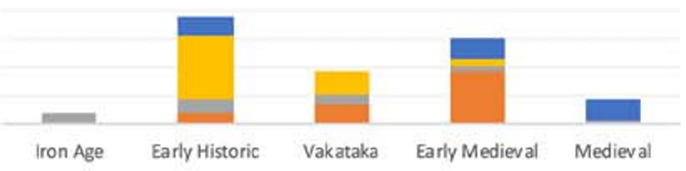

150

1990's

100

50

0

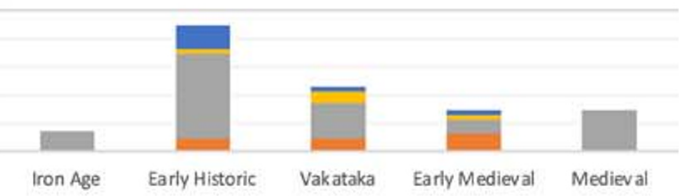

2010's

150

100

50

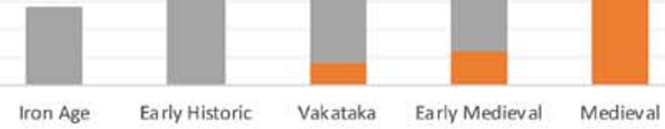

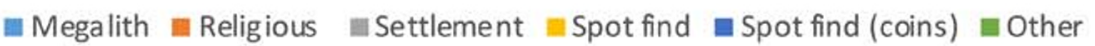

Fig. 7 Chart illustrating the number of different archaeological site types and periods that have been investigated during each decade of research 


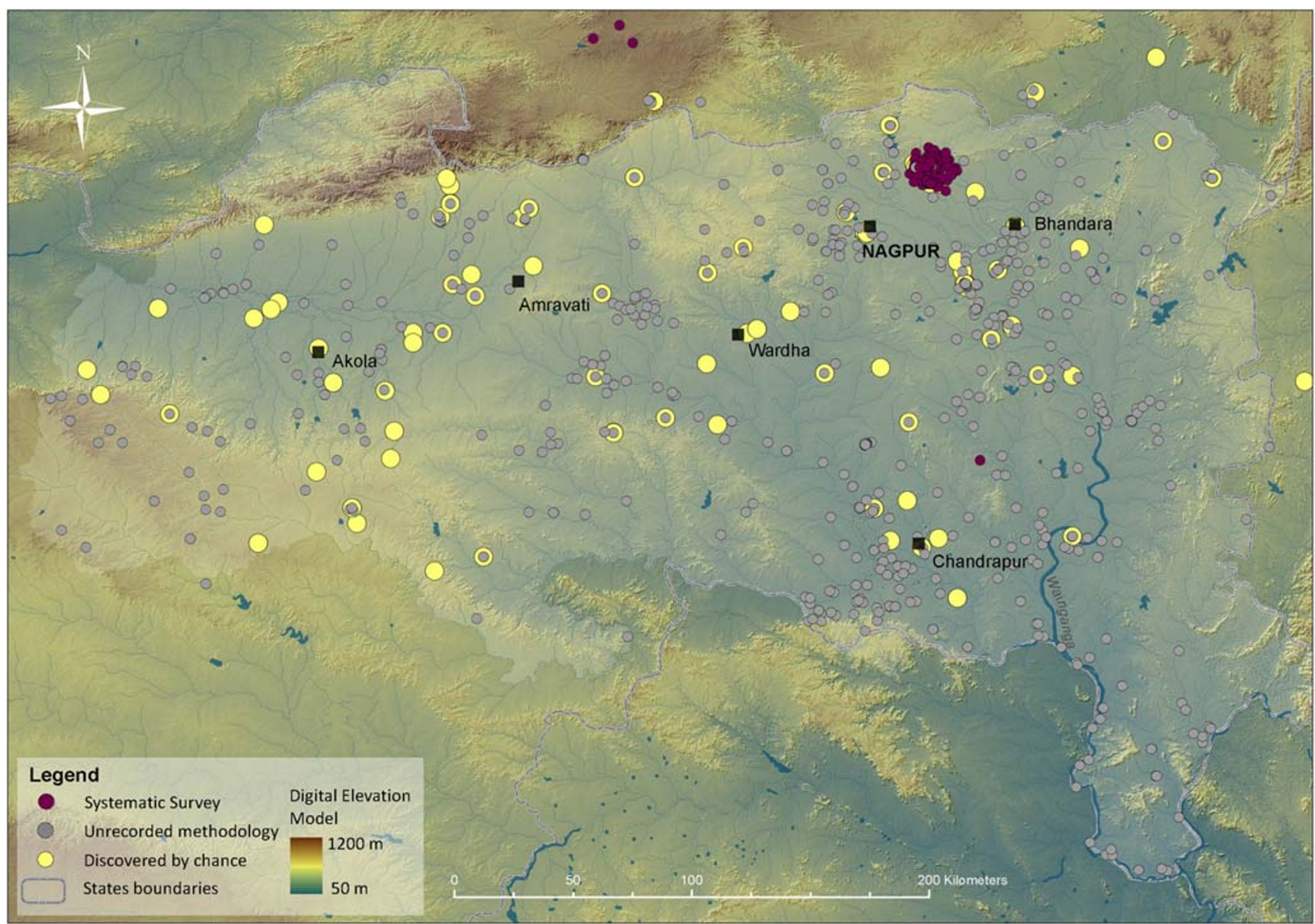

Fig. 8 Map illustrating the known sites in the Vidarbha region that were discovered through surveys, displayed according to the stated survey methods used

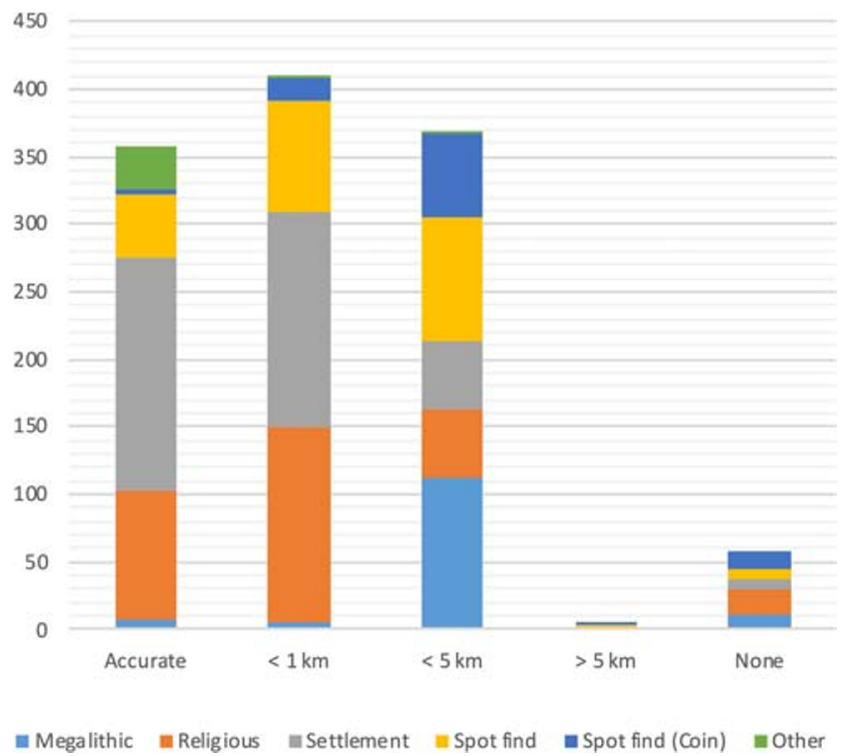

Fig. 9 Chart illustrating the accuracy of site locations in relation to site type the data presented in published reports were generated. It thus becomes very difficult to validate them.

Survey methods, too, are rarely made explicit (if stated at all). We all know that the parameters of a survey frame (its size, where it is located, and how it is defined in relation to the thing or things that are being investigated), the scale of survey (whether extensive or intensive), the methods of reconnaissance (whether they be the analysis of remote sensing data, geophysical survey, or the precise mode of fieldwalking), sampling strategies, and methods of recording all have considerable effect on the data that are retrieved. Yet, only two archaeological surveys of this region have been explicit about their methods (Lacey 2016; Smith 2000). In all other cases we again have to infer them. Given the heritage and tradition of survey methods in South Asia, it is fairly safe to assume that most, if not all, previous surveys in this area have used some form of informant-based survey - what, in South Asia, is usually referred to as "village-to-village" survey (see Shaw 2017). Here, working on the principle that modern villages are located every two or three kilometers across the landscape, and that the residents of these villages are more attuned to the existence 
of extant remains or artifacts in the plough soil, modern villages form the foci of archaeological enquiry. However, even within this general approach there is still considerable variation as to how it can be implemented according to all of the factors that have just been reviewed. ${ }^{15}$ This in turn means that we are left with considerable uncertainty as to how representative the data from those surveys might be (Fig. 8).

\subsection{Dating sites}

The potential impacts of these methodological biases on our understanding are exacerbated by the ways that sites and remains are dated. Very few sites in the region have been dated using absolute methods. Only three of a total 54 excavated sites have radiocarbon determinations, namely, the settlements at Adam, Nagpur District (Nath 2016); Bhon, Buldana District (Deotare 2007, 2008); and Paturda, Buldana District (Deotare 2007), and there are many questions surrounding their reliability. These include the lack of clarity about the nature of the contexts from which the samples were collected, exactly what samples were collected for analyses and why, and whether or not the results have been calibrated and the calibration curves that were used. Instead, sites and individual spot finds tend to be dated using relative methods - on the basis of the material remains that define them with reference to wider typologies of style. This is common practice in many parts of the world, but the chronological resolution afforded by relative dating in South Asia is severely constrained by the methods used to retrieve the dating material. Thus far, excavations in South Asia have tended to focus on the identification and definition of broad stratigraphic layers that potentially include many individual deposits, with each layer representing a "cultural period" covering many hundreds of years. The problem with this is that with stratigraphic layers thus defined, it is impossible to disaggregate the archaeological remains that were found within them. As such, and with no small degree of circularity, we end up unable to improve our chronological understanding of artifacts on the basis of their stratigraphic position, and because of this we are unable to date these broad stratigraphic layers any more precisely. ${ }^{16}$ So, we end up with "layers" relating to two or three centuries of time, which are grouped together into "cultural periods" and (due to reasons outlined earlier) labelled with reference to the political dynasties that define our understanding of the past. Not only does this make it hard to reconstruct a more finely grained picture

\footnotetext{
15 These range from the size of the total area being surveyed, the methods of enquiry used (exactly who is talked to, the questions that are asked, how much time is invested in these enquiries), what is being deemed worthy of recording (which is linked to the survey aims discussed above), and how those things are recorded (e.g., simple presence or absence, sampling, total recording, etc.).

${ }^{16}$ For a more extended discussion of this in the context of South Asia, see Hawkes (2014); and for specific reference to the dating of archaeological contexts dating to the "Vakataka period", see Kennet (2004).
}

of the history of activities at individual sites, but it also means that when we find material for which there is no clear typology on the surface of a site we can only date that material (and by extension the site it defines) according to these same broad periods.

The situation is slightly better with the dating of material such as sculptures, inscriptions, and coins, which are less dependent on excavation bias and can draw on much more developed iconographic lexicons and typologies or specific details mentioned in texts. Yet despite this, the very fact that there are these inconsistent dating frameworks for different types of material makes it difficult to compare them and the sites where they are found. This is not helped by the fact that different people operating within (and contributing to) different silos of knowledge use different terminologies. Regardless of whether individual sites and/or remains might be dated to a single moment or an extended period of time, we can identify four main ways of presenting their date: precise dates, to the level of a single year (usually recorded in inscriptions); individual centuries; the rule of individual dynasties; or broad periods of time that cover multiple centuries. The latter is particularly problematic, with periods of time being defined on the basis of: royal dynasties (e.g., the Mauryans, Satavahanas, Rashtrakutas) under whom significant societal and cultural developments are deemed to have taken place, yet who, in some instances, may not have ruled the region directly ${ }^{17}$; (often very vague) archaeological eras such as the "Iron Age", "megalithic" and "early historic" and "historical" periods that are defined on the basis of perceived changes in the archaeological record ${ }^{18}$; and historiographic designations such as "ancient", "early medieval", and "medieval" that are rarely defined at all. ${ }^{19}$ These are all used interchangeably with each other. For this region alone, we note 175 different ways of defining the period or time to which a site might be dated. Thus, in order to compare archaeological material, it invariably becomes necessary to reduce our chronological understanding to the lowest common denominator, and we end up continuing to make recourse to broad, vague and unsatisfactory terms such as the "megalithic", "early historic", "Vakataka", and "early medieval" periods. Each of these might encompass anywhere between three to six centuries.

\footnotetext{
${ }^{17}$ The question of the rule of the Mauryans and Satavahannas over the region is particularly problematic. Both are dynasties that, due to the presumed extent of their territories and perceived ubiquity of material culture within those territories, have come to define entire periods of South Asia's past. With this comes a number of assumed societal and cultural developments in the territories they are assumed to have ruled. However, the precise extent of their territories and their boundaries are by no means certain; and this particular region may well have been on the periphery of both. For further discussion, see Sawant (2012).

${ }^{18}$ These labels are used across South Asia, but they have varying (and rarely agreed) temporal parameters in different regions. The precise delineation of periods is rarely made clear when they are used.

${ }^{19}$ For discussion of the periodization of South Asian history, see Kosambi (1956), Singh (2009), Thapar (1968) amongst others.
} 
These limitations are further compounded by the fact that we often have very little idea of the bases of the reported dates. Sites and remains are often reported as belonging to a particular date (however general that may be), but the evidence that lies behind that attribution - the specific pottery types, details of the style of sculptures, or descriptions of coins - is rarely provided. Instead, we have to trust what is being reported, even though we know that there is considerable uncertainty and inconsistency that makes it virtually impossible to move beyond the broad time slices that are used.

\subsection{The interpretation of archaeological sites}

Perhaps unsurprisingly, these biases and lack of information affect our understanding of the different types of sites in the region in various ways. It is worth being explicit about these. Thinking first about settlements, because most reconnaissance surveys appear to have been carried out to locate and provide a broad assessment of their date they are not recorded in any great detail once they have been found. ${ }^{20}$ Existing reports are usually missing such things as full descriptions of the archaeological features that define these sites, the dimensions of habitation mounds, or the extent of surface scatters, or how these might relate to issues of site taphonomy, as well as specific details and quantifications of surface remains. Without this information (missing from $92 \%$ of settlement sites), it is not possible to say very much about how the surface assemblages (or other characteristics) that define a settlement might relate to subsurface remains, or to identify changing patterns of settlement and the activities that took place within a settlement over time. When settlements are excavated, because the stated aim is often to establish their "cultural sequence" instead of the activities that took place within them, ${ }^{21}$ the methods that we assume were used are understandably coarse. They are purposefully designed to reveal and record a stratigraphy that is already expected to comprise successive layers,

\footnotetext{
${ }^{20}$ Two things are at play here. First is the notion that we cannot really tell much about a site from surface remains alone, and that we can only say anything of substance through excavation. This ignores decades of literature from other archaeological contexts that proves the value of surface survey (e.g., Adams 1981; Aston 1985; Binford 1982; Dunnell and Dancey 1983; Flannery 1976; Keller and Rupp 1983; Lewarch and O'Brien 1981; Plog et al. 1978; Schiffer et al. 1978; Sullivan 1998; Willey 1953). Second, this is symptomatic of the wider issue of thinking that we "know" things - if the remains of what appears to be a settlement are identified, the site is immediately categorized as a settlement or a habitation, and the various activities and practices that took place at that site in the past (the ways in which people lived, what they did, how they interacted with one another) are assumed to be "known" before the site is even excavated.

${ }^{21}$ A hangover from the immediate post-Independence era, when the then Director General of the Archaeological Survey of India, Mortimer Wheeler, realized that there was not sufficient grasp of the chronological framework of the archaeological heritage of South Asia, and so implemented a programme of rapid small-scale excavation to quickly and expediently date sites. However, this was only ever intended as a preliminary evaluative measure prior to more extensive and detailed excavations (Wheeler 1954).
}

each one older than the last. They are not always sensitive to discrete contexts that may only appear as thin $5 \mathrm{~mm}$-thick lenses of soil recognized only on the basis of subtle color or textural changes, or the complexity of taphonomic processes that can (and usually do) make neat horizontal stratigraphic sequences a rarity. In addition, apart from three notable exceptions (Deo and Joshi 1972; Nath 2016; Sontakke et al. 2016), sites have been dug on a very small scale, with excavated areas generally accounting for less than $2 \%$ of the surface area of a site (Hawkes 2014). This means that we are unable to say very much about the activities that took place within and around settlements. Indeed, this is reflected in way that results are often presented. These tend to be simple lists of the artifacts that are found in layers that are equated to "cultural periods", rather than the results of the analyses of those artifacts and the contexts in which they were found, and the social, cultural, economic, and environmental implications of this information. We are instead left with a situation where we simply have "settlement" or "habitations" as a site type, and little sense of what this denotation might mean. ${ }^{22} \mathrm{We}$ end up, as outlined earlier, imposing certain assumptions about what must have been going on at these sites on basis of wider theories (either derived from written sources or borrowed from wider interpretive frameworks) that may or may not apply.

Religious sites, on the other hand, tend to be investigated to reveal remains for art-historical study, and are conceptualized only in terms of the religious practices that took place within (or, in the case of circumambulation, around) the central monument that defines the site. As such, it is only ever these central monuments that are recorded and excavated. The other archaeological dimensions of the sites in which they existed are rarely explored. This means that we are left with little (archaeological) knowledge of the other activities and practices that may have taken place at those sites - from the habitations of monks and nuns, to the various actions that all sorts of visitors may have performed at these sites in addition to participating in the main ritual "event." For exactly the same reason, we are also left with little or no understanding of the life-span of these monuments. Instead, they exist in our historical imagination only in terms of the century within which they were built. ${ }^{23}$ Further, and due to the

\footnotetext{
22 This also causes further methodological and conceptual problems. By defining sites as "settlements" or "habitations" without clearly defining (or necessarily understanding) what this means, a great amount of nuance and variation in settlement activities is ignored. Further, in defining sites in this way, many may be mis-identified completely. "Settlement sites" are usually identified and defined on the basis of the presence of certain material remains (such as brick and pottery) or taphonomic features (such as the presence of a characteristic pale colored "habitation soil" visible in natural exposures) that are more usually associated with habitations than other types of sites. This being the case, one can easily imagine other sites that might give off a similar surface signature (e.g., a residential institution such as an early wood- or brick-built temple that was home to people) being labelled instead as "settlements."
} 
same bias inherent in the aims with which such sites are surveyed and excavated, once they are found, they are sometimes not recorded fully. Unless we have full and detailed descriptions, and images of the remains that define them, we are unable to say very much about them archaeologically. They become disassociated from their materiality, and exist only as written references to "Hindu temples" or "Buddhist caves." Thus, just as we saw with settlements, we end up with little understanding of how they were used and functioned as archaeological sites. The activities that took place at them, and how they fitted in with wider societal dynamics around them are understood solely with reference to textual understandings of the religions as they existed philosophically and historically at a specific point in time, or with recourse to wider theories about religions, rather than on the basis of a continuum of material remains from the sites.

Another related category of sites that we know of in the region, yet one that is classified as totally distinct, are "megaliths." Despite the monolithic nature of this denotation these are a diverse group of monuments that date broadly to the first millennium BCE. ${ }^{24}$ Such are their predominance they would have formed a very important part of the sociocultural context from which elements of society and culture during the reign of the Vakatakas would have grown. The megaliths in this region have been a major focus of archaeological attention for the last sixty years (see Mohanty and Thakuria 2014; Sawant 2010). As a result, a broad typology exists: monoliths or standing stones, dolmens, cairns, and stone circles (Thakuria 2009). But for all the reasons highlighted above there is much the same inconsistency of reported information about these sites. Reports of the existence of megaliths are mainly lists of site names with few details about the sites themselves, and the interpretation of excavation results are plagued by similar constraints of scale and chronology (as discussed above). ${ }^{25}$ Thus, "megaliths" remain an uncomfortably broad and fuzzy category in which we lump what are essentially entirely different classes of things: monuments and burials. Just as with settlements and religious sites, our understanding of the activities that took place at and around these megaliths, how they were related to settlements, and their (potentially highly variable) cultural meanings and significances are extremely limited. So again, interpretations on any of these fronts tend to be made with reference to a series of assumptions and things that we

\footnotetext{
${ }^{0}$ We have no information about how or why people in the past selected these locations to construct monuments on, what religious practices involved, how long they were used as ritual sites, the ways in which activities may have changed over time, and who might have been involved in these activities.

${ }^{24}$ In some parts of South Asia they are known to continue into the early first millennium CE (Moorti 1994).

25 The only difference being that megalithic burials tend to be limited to only one or two phases of deposition, so do not suffer to quite the same extent from reducing complex settlement stratigraphies to few layers.
}

think we "know" rather than necessarily having complete basis in the archaeological evidence. ${ }^{26}$

Our ability to use and understand the evidence of isolated finds from the region is similarly constrained. This is a somewhat artificial category of different artifacts (comprising such things as fragments of carved architectural remains, inscriptions, quern stones and coins), about which various and different things can be said. As material objects they embody all sorts of processes, practices and intentions, and are, in themselves, repositories of incredibly diverse forms of evidence. Yet these objects, irrespective of what they are and what they might embody, are usually recorded and reported very superficially; often simply with reference to their existence somewhere within a named village. The exception to this general trend is inscriptions, which (for reasons outlined above) tend to find their way into a separate stream of scholarship and are written about in terms of the text of the inscription (Hawkes 2014), if not the material objects on which they are carved. The lack of basic information about this general class of isolated finds obviously limits what can be said about them. This is not helped by the fact that due to the way they were discovered, they are further removed from their context. Here, we can think about "context" on at least two different levels. The first is the context of their find spot, which includes both the mode of their discovery (whether, for instance, they were unearthed in a field, or found in the possession of the person that found them), and where they were discovered. If they were found in the ground, it would be useful to know what other remains might have been associated with them, or something of their environmental setting. The second is their societal and cultural context, from which they are divorced by virtue of the way that other sites around them have been identified, recorded and studied. The result is that our understanding of these objects is severely constrained. While we might be able to make fresh observations by considering them from a material cultural perspective, due to everything that has been discussed above we soon reach a point where we either: (a) are unable to say very much due to the limited amount of evidence available; or (b) again find ourselves having to fall back on a series of constructs that are, at root, based on a series of assumptions about how various aspects of society "worked." This is best exemplified by the study of copperplate inscriptions, which until recently have been viewed in total isolation from the contexts in which they were found and existed and have been interpreted with reference to wider socio-economic

\footnotetext{
${ }^{26}$ For example, the existence of various craft objects such as beads and tools found at megalithic sites, as well as the technological expertise visible in the production of those objects, are frequently taken as indicators of certain socioeconomic activities such as "commercial exchange" (e.g., Thakuria et al. 2015). However, there is little contextual or material evidence to support these interpretations or enable us to identify how those activities may have been organized, controlled, mediated and so on. All of these interpretations are, instead (and without it being made explicit) assumed with reference to wider social and economic theory.
} 
paradigms (Hawkes and Abbas 2016). This is also the case with coins that as a class of object have the potential to tell us an enormous amount of information but that due to the space they occupy in archaeological scholarship are often furthest removed from any archaeological context by the time they are reported. ${ }^{27}$

\subsection{Other missing data}

From the preceding review, we can see that a great deal of bias and missing information affects what we can say about the existing evidence, at least in as much as it has been reported. We are frequently unable to move beyond the most general characterization of archaeological sites, or even think beyond "sites" and artifacts as the only units of archaeological analyses. This is exacerbated by the fact that additional entire categories of information are frequently absent from all site reports. In particular, we might highlight: details of the environment in which the sites and remains existed, and their geographic locations.

Looking first at the environment, we know very little about the specifics of the past climate, soils, hydrology, topography, and plant environment of this region. Other than a very limited number of studies that have explicitly sought to retrieve this information (e.g., Deotare 2006), these data have not been recorded. This limits what we can say about the way people settled, adapted to the natural world in which they lived, and took advantage of their milieu by transforming the natural environment and exploiting its resources in response to individual and collective needs for any number of biological, cultural, economic, or social reasons. The reasons for this are difficult to pin down. The centrality of the environment to human experience is known in scholarship on South Asia (Casile 2014; Jones 2007; Kingwell-Banham and Fuller 2012; Madella and Fuller 2006; Petrie and Bates 2017), but there are also various financial and bureaucratic constraints that affect scholars' capacity to retrieve and analyze relevant samples that would enable us to speak to this topic. Yet deeper than this, we suspect, lie the continued effects of a traditional and enduring conceptual divide between nature and society; as well as a more recent fear of environmental determinism in the

\footnotetext{
${ }^{27}$ Here, a lack of information about their archaeological context and later provenance will always affect our interpretation of coins. Further, the ways these artefacts tend to have been recorded and reported means that we also have very few details about them. There exist a number of criteria that numismatists use to define and classify coins, and certain key characteristics (their size, weight, precise descriptions of both faces, methods of manufacture, and so on) that make it possible to analyze them (see, for example, Kemmers and Myrberg 2011). Yet, due to a tendency by many archaeologists in South Asia to view coins simply as chronological markers, or (erroneously) as quantifiable indicators of the scale of monetary economy, these basic details are often not recorded. Instead, it is thought to be enough to record them simply in terms of the dynasty that issued them (e.g., a "Sasanian coin"), and with no visual representation of the coin being recorded there is often no way to verify this information. All of this means we are sadly unable to say very much about the existing coin remains at all, other than to point out that they exist.
}

study of humanities. These factors have made scholars envisage the environment as a passive backdrop for social actions and societal dynamics. Societal and cultural histories have been disconnected from other environmental dynamics as if they had nothing to do with the ways that political powers developed, empires were built, and political, religious and institutional landscapes were shaped (cf. Morrison 2018), as if sociopolitical and other vulnerabilities to environmental constraints and catastrophes (which must have taken place in the past too) did not exist (Casile 2017). It is precisely this disconnect that has influenced decades of scholarly practice. This can be seen in the ways that data have been selected, recorded, or discarded and that contexts have been defined, described, reduced, or ignored.

The locations of sites are also not usually recorded in the archaeological literature. The names of villages and administrative units are listed, but with little attempt to situate them in space. Instead, the onus is on subsequent scholars to divine this information. The result is that the existing evidence is yet further divorced from the contexts in which it existed, and another fundamental aspect of human experience is removed from the potentiality of archaeological enquiry. Societal developments such as state formation, the emergence of empire or the growth of a particular cultural hegemony (being the standard preoccupations of scholarship on this region and period) have an inherent spatial dimension, and necessarily involve consideration of things such as the proximity of certain sites to others, environmentally constraining factors, and routes of access and communication. But if we do not accommodate these spatial dimensions into our analyses, it becomes very difficult to look at these topics. Indeed, as one of the main arenas in which people and things exist, space is not only inseparable from our conceptions of time and the environment (both ours and past peoples'); it is also a very important (some would say the most important) framework in which we can usefully consider, measure and analyze them (Lefebvre 1991; Blake 2004).

Thankfully, unlike the paucity of environmental data, this can be ameliorated somewhat by locating known sites in space. Here, the names of the villages and the administrative units where sites are reported to exist become obvious geographical reference points that can be used to locate them. Doing so is not without challenges, however. In South Asia the names of villages and administrative districts change frequently over time. Sometimes, it is clear that earlier researchers have not recorded the name of a village but have instead recorded the local name of a place within a village. Equally, there are a number of different ways of transcribing the names of South Asian villages (as they exist in multiple languages) in Latin script, meaning that spellings can vary considerably. Yet through archival research, tracing additional clues that might point to their location (such as published references to distinctive landmarks), cross-referencing multiple reports with government census data and various 
cartographic resources, it is possible to locate 768 sites, which accounts for $64 \%$ of the total. Still, $432(36 \%)$ remain unlocated. This still leaves us with the problem of the precision with which sites and isolated remains can be located within villages. Here, we are forced to accommodate varying degrees of locational uncertainty. We note that in this area, the average distance between modern villages is $3-4 \mathrm{~km}$. So, for sites recorded as being located only within the wider area of a named village, we can safely assume that they are located within $5 \mathrm{~km}$ of an arbitrary geographical coordinate centered on the modern village. Positive though this might sound, this still means that the archaeological site in question could be located anywhere within a $78 \mathrm{~km}^{2}$ area. Sites that are recorded as being located within a modern village settlement carry with them a factor of uncertainty of approximately $1 \mathrm{~km}$. Only those with precisely defined or easily discernible locations are recorded as accurate in our data set (Hawkes et al. 2020) (Fig. 9).

These degrees of uncertainty do limit the potential of spatial analyses. But at the same time, grounding these sites in space with various levels of precision enables us to visualize the distribution of the existing evidence. First, through plotting all these sites, we can see a clear clustering in particular areas (Fig. 10). If we consider these clusters in relation to modern features, it seems clear that most are located close to modern cities: in particular, and not coincidentally, Nagpur where the State Department of Archaeology and Museums and Nagpur University are based. Both of these institutions are very active in fieldwork, having carried out $44 \%$ of investigations in the region. Second, we can visualize the intensity with which different types of sites have been surveyed and excavated (Fig. 11). Doing so not only shows a similar proximity to Nagpur, but also a preference for megaliths and settlement archaeology. This supports our earlier suggestion that certain types of sites have been more popular to previous research and that the basic quantities and proportions of these sites in relation to others may not reflect past reality. We could take this one step further by visualizing where different surveys have been undertaken and so whether they have, in fact, favored particular types of sites over others. Indeed, if we do so we notice that different categories of archaeological sites appear to be the predominant site type in different areas of the region (Fig. 10). There are large parts of the region in which most known sites are "settlements", and others where "temples" or "megaliths" predominate. There is little overlap between these zones. In light of the bias discussed above, this

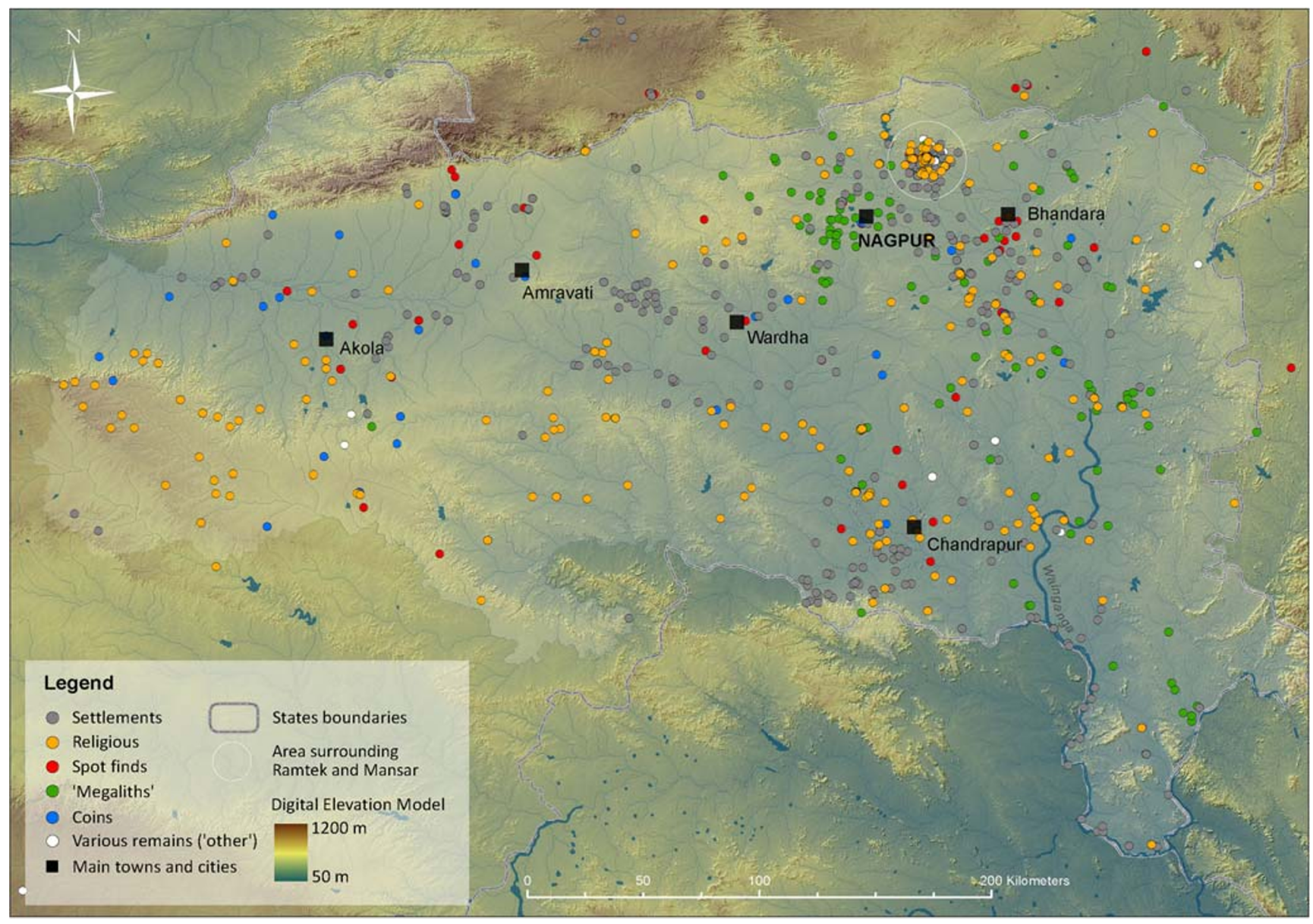

Fig. 10 Map illustrating the distribution of archaeological sites in Vidarbha according to their recorded site type 


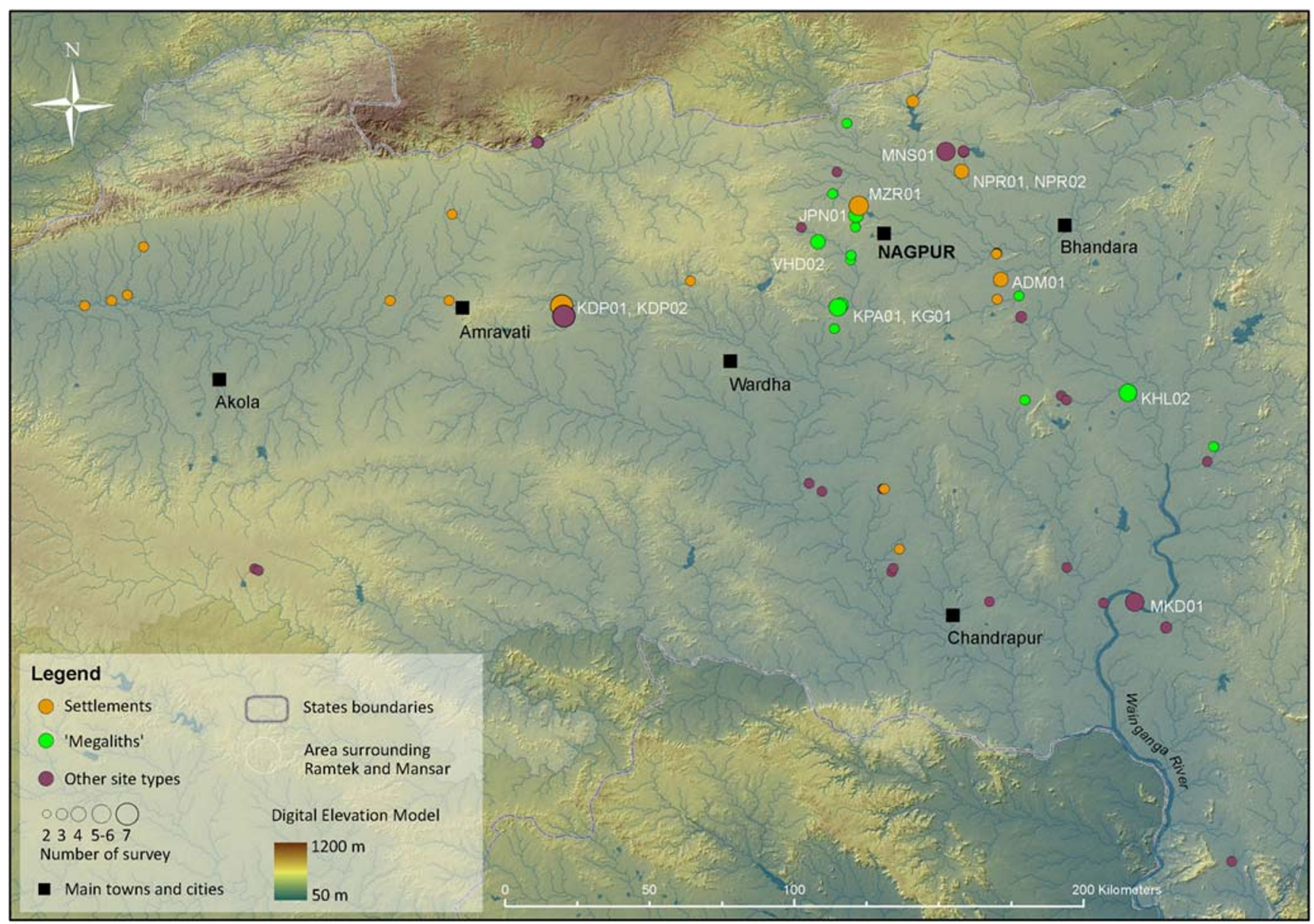

Fig. 11 Map illustrating the locations of archaeological sites in Vidarbha that have been investigated more than once, and the number of times they have been investigated

zonal patterning perhaps tells us even more about the foci, priorities and approaches of previous investigators. Despite not always stating their research aims, the plotting of all of the known sites in the region allows us see that many previous surveys of particular areas have targeted specific types of sites or remains in order to meet what appear to have been somewhat selective objectives. This also implies that a great deal of information may have been missed through such selective surveying - not only other types of sites that fell outside foci of interest, but also other aspects of the landscape remained invisible (visually and cognitively) to the investigators. This is something that we have begun to test in subsequent phases of our research, and that will form the basis of works that are forthcoming.

We can see at least two factors at play here. On the one hand there is the methodological issue of survey bias, which is an all too familiar feature of archaeological practice in a number of places around the world (e.g., Dunnel and Dancey 1983; Hawkins et al. 2003; Schiffer et al. 1978; Sullivan et al. 2007). Equally, and far more serious, are the existence of certain conceptual constraints. That distinct areas of the known archaeological landscape are populated by particular types of sites and that other types of sites have not been found in those areas is due to either: (1) the fact that other types of sites are not there, or (2) the fact that those areas have not been examined very often. In South Asian archaeology there is a healthy tradition of not critically assessing previous scholarship. Sites, once excavated, are not usually excavated again (unless they are very big and very famous) (see Kennet et al. 2020). In a similar vein, it would appear that areas of this region, once surveyed, have not been examined again. Or, if they have been, it is because they have already been identified as areas with high potential for finding particular types of sites. That this is the case is further supported by considering how many times individual sites have been examined. Doing so reveals that in comparison to the total number of sites in the region, only very few sites in the region (80 out of 1200 ) have been examined more than once (Fig. 11).

Taken together, consideration of the archaeological evidence from the region shows that there is considerable bias in what has been investigated and how that evidence has been collected. An uneven and non-representative coverage of sites, a poor handle on their dating, a limited grasp of artifact typologies and what evidence exists, the small-scale nature of 
excavations, little environmental data, and (until this study) no spatial context all limit what we can say about a number of topics. These include the range or nature of activities that took place within sites - both settlements and religious sites - or indeed conceptualize very many other types of "sites" that might extend beyond these two basic categories; the built environment; continuities and discontinuities of site occupation; the ways in which people and ideas were related with each other across space; the ways that individuals, groups, and communities interacted with the natural environment, using its primary resources; and how these various aspects of human existence changed over time. As such, we can see that there is a yawning gulf between the interpretive frameworks within which archaeologists have thus far sought to operate and the evidence at our disposal. For all these reasons, and thinking back to the themes of research that have so far defined the study of the period and region in question (the mid- to latefirst millennium BCE), we are far from having sufficient evidence to identify coherent or detailed patterns of urbanism, agricultural practices, or to define ideologies (beyond those recorded in texts), let alone support theories of agricultural intensification, consider the relative feudal nature of society, chart development of the state, or the relation of any of these things to religious institutions. Our interpretations of all these factors still rest on particular readings of texts, and a series of normative ideas that however reasonable they might seem are still rooted in a series of assumptions about the way that phenomena such as "trade", "agriculture", and "society" worked. In this area at least, the reason for this disjuncture between theories and evidence appears to be due to three fundamental issues: practice, environment, and space.

\section{Possibilities}

Much as it is important to be explicit about the limitations that exist with any data set, doing so does not mean that we should disregard the data we have because of those limitations. That would be too obtuse and not very constructive. The archaeological record is always going to be limited and incomplete. By their very nature, the material traces of past human activity are just that: trace remains. The significance of remembering this is twofold. On the one hand, it means that we (as both archaeologists and others with vested interests in the findings of archaeological research) should not labor under the mistaken impression that archaeology deals exclusively in empirical "truths." On the other hand, it serves as a reminder that we can only (and should always strive to) make the best of what we have. As long, that is, as what we say is supported by the evidence being invoked.

With this in mind, returning to the basic units of archaeological enquiry in this context has opened up a number of potential directions for research. For a start, the very act of compiling this data set and locating the data on the ground means that we are now able to reduce the gap between the evidence and the theoretical frameworks used to understand them. In establishing a picture of the existing evidence, we have ended up assembling information pertaining to 1200 archaeological sites across a $100,000 \mathrm{~km}^{2}$ area. This is a significant data set and one that is larger than has hitherto been recognized in any scholarly works on this region. Further, for all that there are (considerable) limitations with these data, locating them in space allows us to consider them in far more connected and connective ways. It is not only possible to explore the spatial relationships between known sites and what they might be deemed to reflect, but also to connect them with other spatial information that is readily available in the scientific literature of other disciplines and that can be derived through the analysis of satellite imagery and paper maps (e.g., data relating to the geology, soils, landforms, and hydrology of the environment). This enables us to explore the temporal dimensions in which people existed in new ways, and move beyond traditional, limited (and limiting) unilinear chronologies that are defined on the basis of dynastic names and cultural periods. For example, we could accommodate and explore the different scales of time over which environmental and societal processes took place. We could also consider the ways in which "time" itself was an important factor in peoples' lives - as a constraint, a seasonal cycle, an inherent aspect of movement across the landscape, and a fundamental consideration in crop cultivation. Thus equipped, investigating the spatial and temporal relationship between archaeological sites and the environment provides us with basic and much needed evidence base to tackle a number of issues. Indeed, establishing an altogether material-environment-space-time framework for the analysis of the past is a necessity if we want to address complex matters such as societal and cultural change (or other enduring concerns such as "state formation") in more meaningful ways.

Thinking along these lines, there is no end of things that could be examined. It really depends on the questions that we would like to ask. It is certainly not the intention here to try to shape or articulate the research agenda for continued archaeological research across this large area. That said, it is possible to highlight some of the potential directions for future research that are suggested by the evidence we have. If we do want to return to some of the current "culture historic" questions relating to state formation, or the social, economic and political changes that may have accompanied the rule of the Vakatakas, there are a number of potential avenues of enquiry. For instance, and with all of the above limitations firmly in our minds, having this data set does enable us to look at the broad-scale changes in settlement over time, from the "Megalithic" to the rule of the Vakatakas and beyond. ${ }^{28}$ In

\footnotetext{
${ }^{28}$ Albeit, with the caveat that we cannot yet extrapolate too many interpretations of the data across the region as a whole. As discussed above, this is due to the way in which previous scholarship on particular topics and time periods has tended to focus on particular areas.
} 
doing so, it would be possible to both: (a) situate any perceived historical changes in a wider material context; and (b) interrogate the evidence that constitutes this wider context to identify the societal and cultural changes that might be reflected by the archaeological evidence. Indeed, it is precisely this addition of a multi-scalar perspective that enables us to connect what is essentially a gazetteer of sites to other layers of information. Here, and while (again) still mindful of all of the limitations of the existing data, we might usefully identify changes in settlement patterns and the density of occupation as indicated by settlement sites (broadly defined), and infer dimensions of socio-economic and political development and organization over time. It would also be interesting to investigate how these changes are related, spatially, temporally and environmentally, to the practice of land grants and the foundation of new temple institutions as reflected by the find spots of copperplate charters and temple sites (Hawkes and Abbas 2016). Doing so would enable us to consider how these practices were embedded in social structures and see whether (and if so how) they were accompanied by any change in the ways that people lived. Equally, we might assess the time that it would have taken to travel across space between places, between realms, across natural barriers. In turn, this would provide us with basic and much needed spatio-temporal framework to get to grips with certain aspects of the formation of the Vakataka state, the consideration of which (as intimated earlier) includes territorial dynamics and processes, "core-periphery" structural relationships, politico-economic expansion.

At the same time, there are other aspects of this archaeological landscape and sets of social, cultural, political, economic and environmental relationships on which we can focus to great benefit. Perhaps most obviously the entire topic of religious change as reflected in the distribution of religious sites in relation to each other, wider patterns of settlement and networks of interaction carries with it considerable potential. We have touched upon this in connection to the traditional preoccupation with land grants and temple institutions. Yet over and above this, temple remains are useful markers of the presence of particular religious sects that we also know about from the textual sources (e.g., Bakker 2010). Charting their development and spread over space and time would reveal a great deal of information pertinent to not only the religious history of, say, Hinduism in this area, but also its social and cultural dimensions. In addition, the corpus of existing evidence considered here also reveals the existence of a number of early Buddhist cave sites. This is something that has not been picked up on by mainstream scholarship on early Buddhism in South Asia, with its tendency to focus on the more obtrusive and monumental remains that (coincidentally) provide far more in the way of art-historical material. An examination of the distribution of these sites in relation to earlier Megalithic monuments and wider environmental and settlement data would undoubtedly reveal a great deal of new information about the spread of early Buddhism.

It is also possible to explore various themes that shift the foci of research away from a traditional preoccupation with states and state-level institutions, and in doing so change our frames of reference altogether. Spatial patterns observed on a distribution map can, of course, be more than descriptive. The benefits of this spatial perspective are not only that we can compare the distribution of sites to explore particular themes, but also that we can interrogate this data in different ways. By compiling the multiple attributes and variables for each archaeological site together with spatial and environmental data within a Geographical Information System (GIS), we can begin to explore relationships between data sets. For example, we might look at where certain types of archaeological evidence (perhaps a particular suite of material culture) are located in relation to each other in order to reconstruct particular cultural or economic relationships between people. Or else we might explore how site locations (and whatever activities that took place within those sites that we are interested in) are located in relation to particular landforms or natural resources in order to make inferences regarding the various affordabilities and constraints of the past environment and how these changed over time.

Alternatively, we could use these data, smoothed with quantitative methods to model population densities and consider how these may have changed over time start to develop hypotheses as to why (e.g., Chamberlain 2006). We could also usefully look at the distribution of the archaeological evidence in relation to the environment to identify some of the ways that past human practices might have been defined in relation to water flows, landforms, areas of agricultural potential, proximity to mineral resources, and so on (e.g., Law 2011; Panja et al. 2015). In doing so, it would be possible to begin making some suggestions about people's conceptions of the environment and the landscape in which they lived, were a part of, and that shaped their existence. These are just three or four possibilities among many. The point here is simply to illustrate the potential of the existing data. This can be understood as extending far beyond current (old) issues of societal change and development, and realize that totally different paradigms of continuity are possible.

That said, and bearing in mind all the limitations and constraints of the existing data, we do have to reconcile this awareness of archaeological potential with the fact that we cannot fully get to grips with any of these topics without doing more archaeological research. For all that we can now say far more than was previously realized, such are the scale of the limitations with the data that we come full circle and are forced to admit that we are essentially still dealing with dots on maps and can only interpret what they mean with reference to theoretical frameworks derived either from the study of equally as biased data sets (i.e., the texts) or from wider 
archaeological literature. Yet, here too, we can consider these limitations as potential avenues for research in their own right. By returning to the archaeological evidence in the way we have done here, we achieve a better sense of what needs to be done, and so what must be done in the future. This census of archaeological sites and remains constitutes a valuable starting point from which to plan future investigations. Consideration of the existing evidence clearly signposts where, regionally speaking, the gaps are in terms of research agendas, and geographical, chronological and thematic areas of interest. Armed with this information, we can identify areas that need to be surveyed (and in some instances re-surveyed), and sites that could be excavated (and in some cases re-excavated). Equally, and in a similar vein, we can admit the limitations of the existing data and use the patterns that can be observed to generate hypotheses. For instance, if we consider the distribution of Buddhist sites in relation to earlier megalithic sites in the region (see Fig. 12), we might posit the idea that the early Buddhist community actively sought to establish Buddhist sites in locations that were already imbued with earlier significance. Once we are equipped with such hypotheses, it then becomes possible for archaeologists to devise methods to test them.
There is also something to be said for gathering basic information - getting a handle on the material culture from this region, establishing the first coherent pottery typologies, developing chronological frames of reference, and so onwhich must surely constitute a valid and valuable research aim in its own right. There is a great deal of potential in the application of quantitative methods, which can accommodate some of the known limitations and inconsistencies in the existing data and be used to identify patterns in those data. The systematic sampling for and collection of environmental data would almost instantly transform both what we could do with the archaeological evidence and our understanding of the ancient past. It is also worth pointing out that any and all of these activities would represent far more meaningful and potentially useful endeavor than simply continuing to excavate big obtrusive sites simply because they are there.

In addition to these "potentialities of practice", the compilation and consideration of this data set opens up a completely different area of research: the history of archaeological research itself. There is already a large literature on the historiography of archaeology both within South Asia and, to a lesser degree, within this region. Much of this has been referred to above. However, this scholarship tends to operate on the

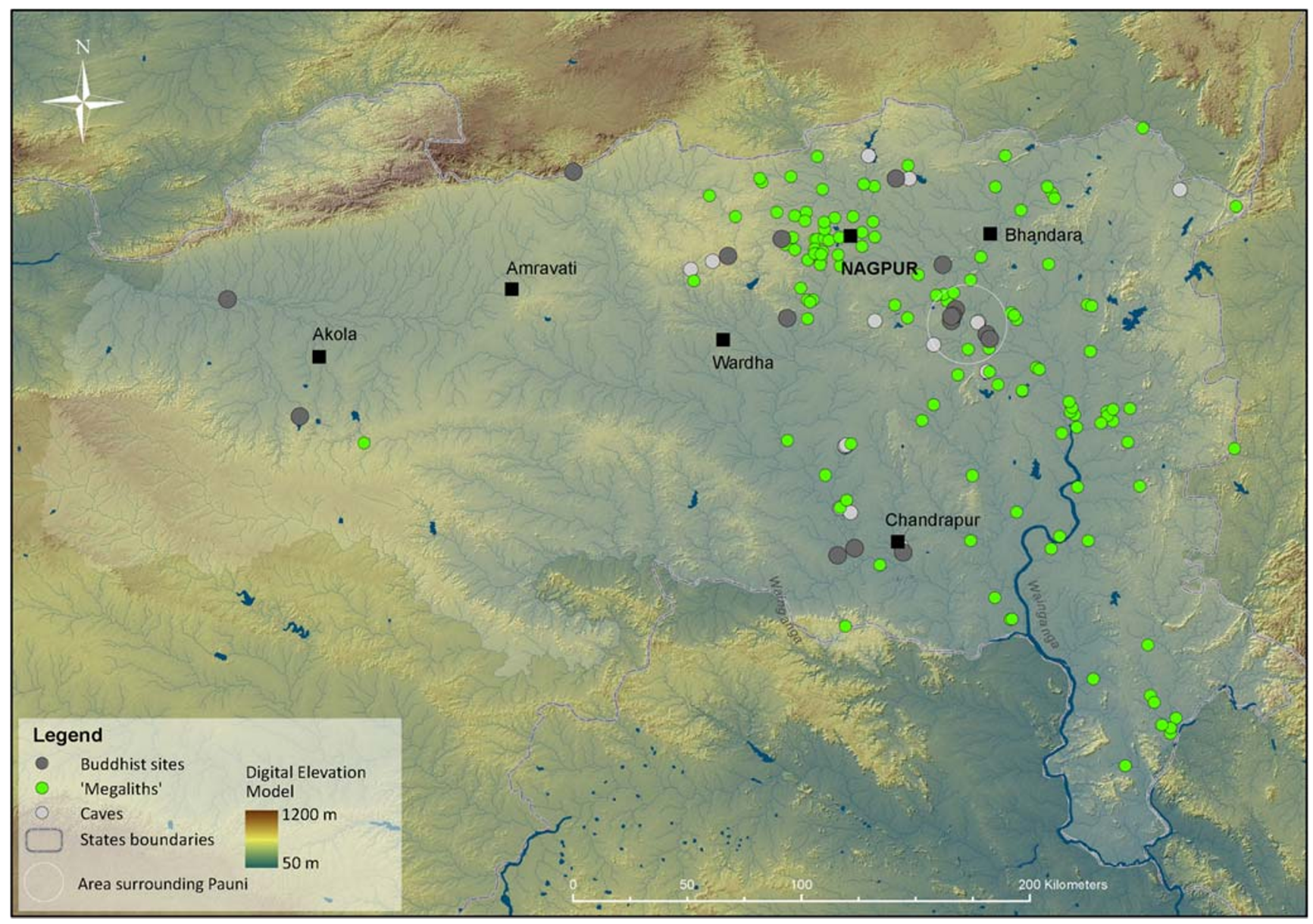

Fig. 12 Map illustrating the spatial distribution of Buddhist sites in Vidarbha in relation to the locations of earlier megalithic sites 
somewhat theoretical level of the ideological frameworks within which various key figures were working; and it is often framed in the context of colonial and post-colonial agendas (e.g., Ray 2007). Crucial though these issues are, what we have here is a data set that allows us to follow in the very footsteps of earlier researchers, seeing where and how they surveyed and excavated - precisely those invisible aspects of the past that have not been examined in preference to what has been examined. For example, when we consider the different ways sites have been categorized, they reflect how past scholars thought about those sites. Similarly, the ways artifacts have been documented and understood speak of how people thought about those remains and what they saw as valuable about them. It also speaks of subjects, objects, and data that have been totally ignored and therefore left invisible. In examining these factors and charting them over time and space, we would be able to access and map how we have developed our archaeological knowledge, and why and how we think about what archaeology has meant for different people. In doing so, we start to move into interesting new territory (at least as far as the archaeology of South Asia is concerned): that of philosophies of knowledge and their construction.

\section{Discussion and conclusion}

Pausing then to reflect, where has this exercise in returning to the archaeological evidence taken us? What has it done? First and most immediately, it has enabled us to identify the evidence that exists in a particular region. It has also made us aware of the bias and limitations inherent in that evidence. We have seen that in this area of South Asia, the limitations are considerable. There is an absence of a great deal of information that we take for granted in other archaeological contexts. This includes: a fundamental lack of typological and contextual understanding of material culture from certain periods; little understanding of taphonomic processes that affect how we "read" and excavate archaeological sites; a limited idea of the activities that took place within settlements, or that extended beyond the central monuments that define religious sites; an absence of environmental data; little in the way of a spatial dimension in which to situate the evidence that we do have; and only a single temporal frame of reference with which to measure and chart any and all changes that might be perceived to take place - one that is itself defined with reference to the rule of kings and dynasties. Because of these issues, there is a disconnect between the theories people have traditionally sought to explore through archaeology and the archaeological evidence itself. Demonstrating this, as we have attempted to do here, serves to show that we need to exercise care when considering what we can and cannot see in and say about the archaeological record.
Equally, recognizing that there will always be imperfect data sets within archaeological research, we can see that taking stock of the evidence that we have at our disposal opens up multiple avenues for research. Compiling this data set and placing it in a spatial framework enables us to explore and build connections with other georeferenced datasets. In doing so we can identify patterns in the evidence that in turn allow us to make certain inferences about the practices and processes the evidence reflects. There is scope to not only further our knowledge and understanding of existing questions (which in this area are almost entirely derived from and continue to be driven by textual scholarship), but also to investigate new topics. These include, but are by no means limited to: ancient demographics, human-environment interactions, and past conceptions and the making of the landscape. All of these are interesting points of departure from traditional foci of enquiry and represent clear avenues for future research that anyone can explore. Having a clear idea of the factors that limit what we can say of the existing data also helps define agendas for future work. Regardless of the research questions being asked, having gone back to basics like this and seen what the problems with the existing data are, we can now see exactly what areas need to be addressed to make resulting data more "valid" and less constraining. While on another level entirely, it also reveals a great deal of potential for the examination of histories of archaeological research and the creation of knowledge in South Asia.

Recognizing all of this in the context of our case-study area justifies the importance of going back to the archaeological evidence. At the same time, when we return to a broader view, the fact that there is such a noticeable disjuncture between interpretive frameworks, archaeological theories and the available evidence across an area the size of South Asia raises some important considerations. That variable levels of archaeological visibility and relative "qualities" of data clearly exist pose problems for comparative studies. These are not necessarily insurmountable, but must be realized and made explicit. Further, we have to assume that while the specifics of the situation outlined here are unique to this area, there may well be a similar disjuncture between interpretive frameworks and the available evidence in other areas of the world. Indeed, while specific concerns of scholarship might be different, similar disjunctures are common in other areas where the historical past is considered stable and "known." We might cite, for example, the study of the Iron Age in the Levant (Joffe 2002; Levy and Higham 2014) where archaeological studies have long been informed by Biblical accounts; the study of historical periods in China from at least the Zhou period, c. sixth to fourth centuries BCE (von Falkenhausen 1993; Min 2003); and the use of archaeology and history in Island Southeast Asia (Lape 2006). These are by no means the only parts of Asia whose study can bear witness to such a trend. Nor is it necessarily the case that issues relating to the limitations of the 
existing archaeological data and what can be done with them are confined to the study of historical periods. We suspect that if we were to look more closely, similar patterns may emerge in the ways that archaeologists have sought to study certain aspects of the Mesolithic or Neolithic in Asia, with reference to certain ideas and theories of prehistoric lifeways developed in the study of the European context.

Accepting this, we are then faced with the question of whether we can necessarily rely on certain interpretive frameworks without having the evidence to back up our suggestions and ideas. Following this line of reasoning, if we then entertain the possibility that existing interpretive frameworks may not necessarily account for some (really quite large) parts of the world where a great deal of foundational work has not yet been carried out, we must ask ourselves: how sure are we that we do "know" how various aspects of past human existence "worked"? If the archaeology of broad periods across large parts of the world have yet to be studied - as the evidence from South Asia suggests is the case- - how sure are we that certain societal and cultural phenomena, or broad "civilizational" developments operated in the ways we think they did?

So where do we go from here? In South Asia at least, it seems that there is a tension between the need for an evidentiary grounding of our ideas, and the need for ideas to interpret the data. At a most reductionist level, we could argue that we cannot apply any theoretical ideas derived outside South Asia onto the South Asian record. Doing so might be repeating earlier mistakes by too simplistically and uncritically transposing certain interpretive frameworks, or falling back on preconceived notions as to how sociocultural or economic structures "worked" in any given context. That said, we cannot trust that examination of the data alone in isolation from the benefits of wider thought will give us the answers we want. There are the obvious dangers here of engendering too positivistic an approach, resulting in too myopic a view of the grounded data. We will always need theories to make sense of the data, and comparative studies have great value in stimulating ideas, forcing us to revisit concepts, re-orient our enquiries, and stimulate new research. Of course, this is not the first time that archaeology has been faced with this question (e.g., Shanks and Tilley 2016). In a sense, and as said before, this entire issue can be thought of as a basic problem of analogy, or as an aspect of the wider tension between empiricism and interpretivism in the social sciences. Our own and, we feel, the generally accepted view is that it is both acceptable and welcome to explore the applicability of wider theoretical ideas and interpretive frameworks. But as this study has made clear, central to this has to be a clear and conscious attempt to: (a) revisit the research questions that are being asked; and (b) make sure that we can connect these theories with the existing data. It is only then that we can test and adjust our ideas and interpretations accordingly. Again, this is neither a new nor profoundly important point. However, it is one that is often forgotten. And the fact that it is forgotten is not always realized by those who lay claim to "knowing" what is innovative and new in archaeological method and theory. Quite aside from the study of historical periods in South Asia, as archaeologists we will always need to remind ourselves of what we really "know." Whether it is in the interests of quantitative accuracy and resolution, or to ensure that what we can infer from the archaeological data may have been the case. Doing so enables us to be sure that we can say what we want to say. It is also a crucial step in developing new research agendasand a much more important one than simply jumping on the latest bandwagon $d u$ jour.

What this need to continually ensure that we know what we think we know actually means in practice is an equally important concern. As we have seen in South Asia it is often the case that we cannot "ground" our theoretical ideas in the existing data because the resolution of those data is so low. This means two things. First, regardless of our theoretical perspectives and the data sets at our disposal, ensuring sound archaeological practice is absolutely key. We are not going to be able to answer the research questions quite as well as we would like if the data being used have not been generated using strategies designed to answer those questions. Second, there is clearly a need for and great value in doing foundational research. As we have seen here, there are immense geographical, cultural and temporal areas where a great deal of foundational research needs to be done before we can even begin to compare certain ideas. In South Asia we need things like a typological and chronological understanding of most artifact classes and a basic grasp of the environment in which people were living before we can begin interrogating and interpreting the archaeological data we already have and will continue to find.

This in turn opens up some important considerations that extend far beyond the scope of this paper. When we realize that we still need to establish such basic things as pottery typologies for entire millennia on a subcontinental scale, there is perhaps a need to recalibrate our concept of "value." Right now, at least in the West, foundational work is not as valued as perhaps it once was. We can see this in the way that "international journals" (by which we mean those edited and published in the United States, Europe, and Australia with welldeveloped international distribution networks) no longer publish reportage articles such as preliminary reports of surveys and excavations, or the presentation of artifact typologies. Such studies are not deemed to have as much "impact" as more synthetic or overtly research-oriented papers. The reasons for this are complex and certainly worthy of further scrutiny. Without wishing to digress we suspect that such analyses would point to at least two factors. The first, and as we said at the outset, is the widespread sense that archaeology as a discipline has already figured out certain topics. Whether consciously articulated or passively received from the certainty with which much academic literature is written, the 
pervasiveness of this notion leaves little room for basic foundational research. This is because according to this chain of reasoning, the only things that can be considered "innovative" and "interesting" are the next big ideas that we have not yet figured out, or the next whiz techniques that have yet to find an archaeological application. The second factor, and very much a corollary of the first, is that within academia the value and worth of scholarship has become conflated with the question of whether it will attract funding. This has contributed to a commercialization of research and professionalization of academia wherein some (thankfully not all) individuals appear more interested in securing grants and gaining promotions than in the research itself. It has also led to a situation where the research projects that secure large grants are the ones that help determine the future direction of the discipline. This in turn only helps to perpetuate the notion that archaeology, as a discipline, has figured out certain problems and that we have the answers to certain questions. Indeed (so the implicit logic dictates), this has to be the case in order to justify moving on to the next (funded) idea.

Returning to the matter at hand, it would seem that the challenge for those working in areas where foundational research needs to be done is to have a clear sense of what needs to be done and why it needs to be done, which leads us back to the importance of continually reassessing the current state of archaeological knowledge and understanding. While for those working in other areas - who, through acting as editors of international journals or coordinators of university curricula, collectively function as the arbiters of archaeological importance, innovation and interest - the challenge is to recognize that all of this is the case, and that at times this "big picture" thinking has the unhappy consequence of engendering a particularly insidious type of parochialism. It may very well be interesting and important to explore various "hot topics" (e.g., big data, climate, migration, population genetics, risk, resilience and sustainability) in a particular geographical or temporal context. But as we have seen here, sometimes the justification for and value of research is simply that we do not have a sound understanding of the material culture or environmental history of an area half the size of Europe for at least two thousand years. We might even suggest that there is also a need to revisit certain topics that are generally thought of as having already been dealt with in wider archaeological scholarship. Topics such as the place of empiricism within archaeological method and theory, the archaeology of religion, or the relationships between art and archaeology, or archaeology and texts appear to be no longer de rigueur because the momentum of wider (western) archaeological theory has carried the discipline as a whole on to new topics that are deemed more interesting and important. This being the case, who is to say that such "older" themes should not be explored in other archaeological contexts where, due to a lack of foundational research, they have not been explored in as great a depth?
Given that so many parts of the world have not been examined archaeologically, there is the distinct possibility that revisiting certain themes may well lead to the discovery of new dimensions of those topics that are considered "done."

Leading on from this, it is often muttered in faculties of arts, humanities, and social sciences in Western universities that regional studies have had their moment and are no longer relevant. The reasons for this are complex and have as much to do with how regional studies have organized themselves in Western scholarship as they have to do with changes in research and teaching frameworks within academic institutions and government funding priorities. The point that we would like to make here, however, is that accompanying this widespread sense of the irrelevance of regional studies is an expectation within departments of archaeology that individual scholars should define themselves not by their geographical area of expertise, but instead on the basis of thematic areas of study (e.g., environmental archaeology, landscape, urbanism, and so on) that are shared by others working in other parts of the world. This is expected even when these same individuals continue, perversely, to be defined by others within their own faculties on the basis of their geographical area of study - as "the South Asian archaeologist" or "the South Asianist." Yet if we accept the fact that we as archaeologists cannot operate on a comparable basis across the world, who is best placed to judge someone else's contribution to wider scholarship on a particular theme? Further, how do we know whether wider social theories that have developed over the last two hundred years, but that are essentially based on the study of a tiny sample of the human past, really are (or should be considered to be) universal across the discipline? We would suggest that there needs to be as much acknowledgement of the value of different regional specialisms that we continue to use to label each other as there is for the methodological approaches and themes of research that unite us.

Acknowledgements The archival research required to compile the data presented in this article was carried out in collaboration with the Indian Historical and Cultural Research Foundation, the Institut Français de Pondichéry and The British Museum. Research was carried out as part of the Asia Beyond Boundaries project, an ERC Synergy project funded by the European Research Council under the European Union's 7th Framework Programme (FP7/2007-2013)/ERC grant agreement no. 609823, awarded to Dr. Michael Willis.

Open Access This article is licensed under a Creative Commons Attribution 4.0 International License, which permits use, sharing, adaptation, distribution and reproduction in any medium or format, as long as you give appropriate credit to the original author(s) and the source, provide a link to the Creative Commons licence, and indicate if changes were made. The images or other third party material in this article are included in the article's Creative Commons licence, unless indicated otherwise in a credit line to the material. If material is not included in the article's Creative Commons licence and your intended use is not permitted by statutory regulation or exceeds the permitted use, you will need to obtain 
permission directly from the copyright holder. To view a copy of this licence, visit http://creativecommons.org/licenses/by/4.0/.

\section{References}

Abbas, R. 2016. Report on archaeological explorations of ancient sites of Vidarbha region, Maharashtra. Unpublished report submitted to the Archaeological Survey of India. Nasik: Indian Numismatic, Historical, Cultural Research Foundation.

Adams, R. 1981. Heartland of cities: Surveys of ancient settlement and land use on the central flood plain of the Euphrates. Chicago: Chicago University Press.

Agrawal, A. 1989. Rise and Fall of the Imperial Guptas. New Delhi: Motilal Banarsidass.

Ali, D. 2012. The historiography of the medieval in South Asia. JR Asiat Soc 22 (1): 7-12.

Ammerman, A.J., and L.L. Cavali-Sforza. 1971. Measuring the rate of spread of early farming in Europe. Man 6 (4): 674-688.

Ashmore, W. 2018. Why the archaeology of political ecology matters. Archaeological Papers of the American Anthropological Association 29: 175-184.

Aston, M. 1985. Interpreting the landscape: Landscape archaeology in local studies. London: Batsford.

Bakker, H. 1997. The Vākāțakas: An essay in Hindu iconology. Leiden: Brill.

Bakker, H. 2010. Royal patronage and religious tolerance: The formative period of Gupta-Vākātaka culture. Journal of the Royal Asiatic Society 20 (4): 461-475.

Banerji, H. M. C. D. A (editor). 2000. Indian archaeology, 1994-95-A review. New Delhi: Government of India.

Bauer, A.M. 2018. Questioning a Posthumanist political ecology: Ontologies, environmental materialities, and the political in Iron age South India. Archaeological Papers of the American Anthropological Association 29: 157-174.

Beglar, J. 1878. Archaeological survey of India, Vol. 7: Report of a Tour in Bundelkhand and Malwa, 1871-72, and in the Central Provinces, 1873-74. Calcutta: Government of India.

Bettinger R. L., R. Garvey, and S. Tushingham. 2015. Hunter-gatherers: Archaeological and evolutionary theory. New York: Springer.

Bhaisare, K. 2012. The Vakatakas: Cultural Study in Archaeological Perspective. Unpublished Ph.D. thesis. Pune: Deccan College.

Binford, L. 1982. The archaeology of place. Journal of Anthropological Archaeology 1: 5-31.

Bisschop, P. 2010. Śaivism in the Gupta-Vākāțaka age. Journal of the Royal Asiatic Society 20 (4): 477-488.

Blake, E. 2004. Space, spatiality, and archaeology. In A companion to social archaeology, ed. L. Meskell and R.W. Preucel, 230-254. Oxford: Blackwell Publishing.

Bocquet-Appel, J.P., S. Naji, M. Vander Linden, and J.K. Kozlowski. 2009. Detection of diffusion and contact zones of early farming in Europe from the space-time distribution of $14 \mathrm{C}$ dates. Journal of Archaeological Science 36 (3): 807-820.

Borkar, R.R. 1986. Kunghaada yetheel Paandav Gufa va Shailashraye. Vidarbha Sanshodhak Mandal 1986: 194-198.

Borkar, R. R. 2009. Chandrapur-Gadchiroli Zilhache Puratattav (Prageitihasik Kal Te E. S. 13 Ve Shatak. Nagpur: Suyash Prakashan.

Brughmans, T., A. Collar, and F. Coward, F. (eds.). 2016. The connected past. Challenges to network studies in archaeology and history. Oxford: Oxford University Press.

Campbell, B. 2016. The great transition. Climate, disease and Society in the Late-Medieval World. Cambridge: Cambridge University Press.
Canti, M., and D.J. Huisman. 2015. Scientific advances in geoarchaeology during the last twenty years. Journal of Archaeological Science 56: 96-108.

Casile, A. 2014. Changing religious landscapes in Gupta times: Archaeological evidence from the area of Badoh-Pathari in Central India. South Asian Studies 30 (2): 245-268.

Casile, A. 2017. Pour une histoire de l'Inde médiévale face aux variations du climat. Les nouvelles de l'archéologie 14: 15-23.

Chakrabarti, D. K. 1998. A history of Indian archaeology, from the beginning to 1947. New Delhi: Munshiram Manoharlal.

Chakrabarti, D. K. 2003. Archaeology in the third world: A history of Indian archaeology since 1947. New Delhi: D.K. Printworld.

Chamberlain, A. 2006. Demography in Archaeology. Cambridge manuals in archaeology. Cambridge: Cambridge University Press.

Chattopadhyaya, B. D. 1994. The making of early medieval India. Delhi: Oxford University Press.

Chitale, S.K. 1987. Nagpur Jilhyateel Kutrim Shailashraye. Vidarbha Sanshodhak Mandal 1987: 165-172.

Chitale, S.K. 1988. Vidharbhateel Mahattvapurn Puravashesh. Vidarbha Sanshodhak Mandal 1988: 164-180.

Cunningham, A. 1879. Archaeological survey of India, Vol. 9: Report of a Tour in the Central Provinces, 1873-74 and 1874-75. Calcutta: Government of India.

Denham, T., J. Iriarte, and L. Vrydaghs, L. (eds.). 2016. Rethinking agriculture: Archaeological and Ethnoarchaeological perspectives. London and New York: Routledge.

Deo, S. B and M. K. Dhavalikar. 1967-68. Paunar Excavations 1970-72. Nagpur: Nagpur University

Deo, S. B., and J. P. Joshi. 1972. Pauni Excavation 1969-70. Nagpur: Nagpur University.

Deotare, B.C. 2006. Late Holocene climatic change: Archaeological evidence from Purna Basin, Maharashtra. J Geol Soc India 68: 517526.

Deotare, B.C. 2007. Preliminary report on the excavations at Bhon and Paturda, Buldhana District, Maharashtra. Bulletin of the Deccan College Research Institute 64-65: 87-105.

Deotare, B.C. 2008. Excavations at Bhon, district Buldana, Maharashtra Annual Report of the Deccan College 2006-07: 75-76.

Deshpande, M. N. (editor). 1975. Indian archaeology, 1966-67-A review. New Delhi: Government of India.

Dixit, M. 1954. Madhya Pradesh Ke Puratattava Ki Rooprekha. Poona: Yashvant G Joshi.

Dunnell, R. and W. Dancey. 1983. The siteless survey: A regional scale data. collection strategy. Advances in Archaeological Method and Theory 6: 267-287.

Eraly, A. 2011. The first spring, the Golden age of India. New Delhi: Viking.

Flannery, K. (editor). 1976. The early Mesoamerican Village. New York: Academic Press.

Fleet, J. F. (editor). 1888. Corpus Inscriptionum Indicarum, Vol. III. Inscriptions of the early Gupta kings and their successors. Calcutta: Government of India.

French, C. 2003. Geoarchaeology in action. London: Routledge.

Gaillard, M.-J., A.-M. Lézine, and K. Morrison. 2015. Launching workshop of PAGES' working group LandCover6k. PAGES Magazine 23 (1): 81.

Garvey, R. 2018. Current and potential roles of archaeology in the development of cultural evolutionary theory. Philosophical Transactions of the Royal Society B 373: 20170057. https://doi.org/10.1098/rstb. 2017.0057.

Gilbert, N. and J. Doran (editor). 1994. Simulating societies, the computer simulation of social phenomena. London: Routledge.

Giosan, L., D. Q. Fuller, K. Nicoll, R. K. Flad, and P. D. Clift (eds.). 2013. Climates, landscapes, and civilizations. Washington, D.C.: American Geophysical Union, 198. 
Guha-Thakurta, T. 2004. Monuments, objects, histories: Institutions of art in colonial and post-colonial India. New York: Columbia University Press.

Gupta, P. L. 1974. The Imperial Guptas, Vol. I. Sources, historiography and political history. Varanasi: Vishwavidyalaya Prakashan.

Håkansson, N. T. and M. Widgren (editor). 2014. Landesque capital: The historical ecology of enduring landscape modifications. Walnut Creek: Left Coast Press.

Harle, J. C. 1974. Gupta sculpture. Indian sculpture of the fourth to the sixth centuries AD. Oxford: Clarendon Press.

Hawkes, J.D. 2014. Finding the early medieval in south Asian archaeology. Asian Perspect 53 (1): 53-96.

Hawkes, J.D., and R. Abbas. 2016. Copperplates in context: Preliminary investigation of the study and archaeological settings of land grant inscriptions. Pratnatattva 22: 41-71.

Hawkes, J.D., R. Abbas, A. Casile, C. Lefrancq, and S. Toraskar. 2020. The archaeology of Vidarbha, Maharashtra: A census of known sites and remains megalithic to medieval. Online dataset. https://doi.org/ 10.5281/zenodo.3667657.

Hawkins, A.L., S.T. Stewart, and E.B. Banning. 2003. Interobserver bias in enumerated data from archaeological survey. $J$ Archaeol Sci 30 (11): 1503-1512.

Hendy, J., F. Welker, B. Demarchi, C. Speller, C. Warinnner, and M.J. Collins. 2018. A guide to ancient protein studies. Nature Ecology and Evolution 2: 791-799.

Hodos, T. (editor). 2017. The Routledge handbook of globalization and archaeology. London: Routledge.

Jervis, B. 2018. Assembling the archaeology of the global middle ages. World Archaeology 49: 666-680.

Jha, D. N. 1993. Economy and Society in Early India: Issues and paradigms. New Delhi: Munshiram Manoharlal.

Joffe, A. 2002. The rise of secondary states in the Iron age Levant. Journal of the Economic and Social History of the Orient 45 (4): 425-467.

Johansen, P. 2003. Recasting the foundations: New approaches to regional understandings of south Asian archaeology and the problem of culture history. Asian Perspective 42 (2): 192-206.

Jones, S. 2007. The Toba supervolcanic eruption: Tephra-fall deposits in India and palaeoanthropological implications. In The evolution and history of human populations in South Asia, ed. M. Petraglia and B. Allchin, 173-200. New York: Springer.

Joshi, M. C. (editor). 1992. Indian archaeology, 1986-87-A review. New Delhi: Government of India.

Joshi, M. C. (editor). 1993a. Indian archaeology, 1987-88-A review. New Delhi: Government of India.

Joshi, P. S. 1993b. The Vidarbha Megaliths: A Cultural Study. Unpublished $\mathrm{PhD}$ thesis. Pune: Poona University.

Joshi, J.P., and A.K. Sharma. 2000. Excavation at Mansar, district Nagpur, Maharashtra- 1997-2000. Puratattva 30: 127-131.

Kale, B. 1999. A Study in the Iconography of Hindu, Jain and Buddhist Images from Vidarbha. Unpublished Ph.D. thesis. Pune: Deccan College.

Keller, D. and D. Rupp (eds.). 1983. Archaeological survey in the Mediterranean area. Oxford: Archaeopress.

Kemmers, F., and N. Myrberg. 2011. Rethinking numismatics. The archaeology of coins. Archaeological Dialogues 18 (1): 87-108. https://doi.org/10.1017/S1380203811000146.

Kennet, D. 2004. The transition from early historic to early medieval in the Vakataka realm. In The Vakataka heritage: Indian culture at the crossroads, ed. H. Bakker, 11-17. Groningen: Egbert Forsten.

Kennet, D., J. V. Rao, and M. K. Bai. 2020. Excavations at Paithan, Maharashtra: Transformations in early historic and early medieval India. Berlin: De Gruyter.

Kenoyer, J. M. 1998. Ancient cities of the Indus Valley civilization. Karachi: Oxford University Press.
Kingwell-Banham, E., and D.Q. Fuller. 2012. Shifting cultivators in South Asia: Expansion, marginalisation and specialisation over the long term. Quarternary International 249: 84-95.

Kosambi, D.D. 1955. The basis of ancient Indian history. J Am Orient Soc 75 (4): 226-237.

Kosambi, D. D. 1956. An introduction to the study of Indian history. Bombay: Popular Book Depot.

Kulke, H. 1982. Fragmentation and segmentation versus integration? Reflections on the concepts of Indian feudalism and the segmentary state in Indian history. Stud Hist 4 (2): 237-263.

Kulke, H. 1993. Kings and cults: State formation and legitimation in India and Southeast Asia. Delhi: Manohar.

Lacey, H. 2016. Ramtek and Its Landscape: An Archaeological Approach to the Study of the Eastern Vakataka Kingdom in Central India. Unpublished PhD thesis. Durham: University of Durham.

Lape, P.V. 2006. On the use of archaeology and history in island Southeast Asia. In Excavating Asian history: Interdisciplinary studies in archaeology and history, ed. N. Yoffee and B.L. Crowell, 278306. Tucson: University of Arizona Press.

Law, R. W. 2011. Inter-regional interaction and urbanism in the ancient Indus valley: A geological provenience study of Harappa's rock and mineral assemblage. Linguistics, Archaeology and the Human Past, Occasional Paper 11: 1-800.

Lefebvre, H. 1991. The production of space. Translated by D. NicholsonSmith. Oxford: Blackwell.

Lefrancq, C., J. Hawkes, and R.K. Mohanty. 2019. A typology of practice: The archaeological ceramics from Mahurjhari. Internet Archaeology 52. https://doi.org/10.11141/ia.52.9.

Levy, T. and T. Higham (eds.). 2014. The bible and radiocarbon dating: Archaeology, text and science. London: Routledge.

Lewarch, D., and M. O'Brien. 1981. The expanding role of surface assemblages in archaeological research. Advances in Archaeological Method and Theory 4: 297-342.

Lydon, J. and U. Z. Rizvi (eds.), 2016. Handbook of postcolonial archaeology. New York: Routledge.

Madella, M., and D.Q. Fuller. 2006. Palaeoecology and the Harappan civilisation of South Asia: A reconsideration. Quaternary Science Reviews 25 (11-12): 1283-1301.

Mahaptra, S. K. (editor). 1994. Indian archaeology, 1989-90-A review. New Delhi: Government of India.

Mahaptra, S. K. (editor). 1995. Indian archaeology, 1990-91—A review. New Delhi: Government of India.

Malinowski, B. 1922. Argonauts of the Western Pacific: An account of native Enterprise and adventure in the archipelagos of Melanesian New Guinea. London: Routledge and Kegan Paul.

Margesin, R., J.A. Siles, T. Cajthaml, B. Öhlinger, and E. Kistler. 2017. Microbiology meets archaeology: Soil microbial communities reveal different human activities at archaic Monte Iato (sixth century BC). Microbial Ecology 73 (4): 925-938. https://doi.org/10.1007/ s00248-016-0904-8.

Mauss, M. 1970. The gift: Forms and functions of exchange in archaic societies. London: Cohen and West.

McAnany, P., and S.M. Rowe. 2015. Re-visiting the field: Collaborative archaeology as paradigm shift. Journal of Field Archaeology 40 (5): 499-507. https://doi.org/10.1179/2042458215Y.0000000007.

Menon, K. (editor). 2002. Indian archaeology, 1996-97-A review. New Delhi: Government of India.

Meskell, L. and R. W. Preucel. 2008. Companion to social archaeology. New York: Wiley-Blackwell.

Mill, J. 1817. The history of British India. London: Baldwin, Craddock and Joy.

Min, L.I. 2003. Ji'nan in the first millennium BC: Archaeology and history. Journal of the Economic and Social History of the Orient 46 (1): 88-126. 
Mirashi, V. V. (editor). 1963. Corpus Inscriptionum Indicarum, Vol. V. Inscriptions of the Vakatakas. Ooctamund: Government of India Press.

Misra, R. C. (editor). 2004. Indian archaeology, 1998-99-A review. New Delhi: Government of India.

Mitra, D. (editor). 1983. Indian archaeology, 1979-80-A review. New Delhi: Government of India.

Mohanty, R.K., and T. Thakuria. 2014. Early Iron age megalithic culture of peninsular India and South India. In D. K. Chakrabarti and M. Lal (eds.), History of Ancient India, Vol. 3. Texts, Political History and Administration till c. 300 BC, 343-378. New Delhi: Aryan Books.

Moorti, U. S. 1994. Megalithic culture of South India: Socio- economic perspectives. Varanasi: Ganga Kaveri.

Morrison, K.D. 2018. Empires as ecosystem engineers: Toward a nonbinary political ecology. Journal of Anthropological Archaeology 52: 196-203.

Nath, A. 1998. Further excavations at Pauni 1994. New Delhi: Archaeological Survey of India.

Nath, V. 2001. From 'Brahmanism' to 'Hinduism': Negotiating the myth of the great tradition. Social Science 29 (3/4): 19-50.

Nath A., 2016. Excavations at Adam 1988-1992), a City of Asika Janapada. 2 vols. New Delhi: Archaeological Survey of India.

Opitz, R., and J. Herrmann. 2018. Recent trends and long-standing problems in archaeological remote sensing. Journal of Computer Applications in Archaeology 1 (1): 19-41.

Orengo, H., and C. Petrie. 2017. Large-scale, multi-temporal remote sensing of palaeo-river networks: A case study from Northwest India and its implications for the Indus civilisation. Remote Sensing 9 (7): 735.

Panja, S., A. K. Nag, and S. Bandyopadhyay. 2015. Living with floods: Archaeology of a settlement in the lower Ganga Plains, C. 600-1800 CE. New Delhi: Primus Books.

Petrie, C.A., and J. Bates. 2017. 'Multi-cropping', intercropping and adaptation to variable environments in Indus South Asia. Journal of World Prehistory 30 (2): 81-130.

Pielke, R.A., A. Pitman, D. Niyogi, R. Mahmood, C. McAlpine, F. Hossain, K. Klein Goldewijk, U. Nair, R. Betts, S. Fall, M. Reichstein, P. Kabat, and N. de Noblet. 2011. Land use/land cover changes and climate: Modeling analysis and observational evidence. Wiley Interdisciplinary Reviews: Climate Change 2 (6): 828-850.

Pitts, M. and M. J. Versluys (eds.). 2014. Globalisation and the Roman world: World history, connectivity and material culture. Cambridge: Cambridge University Press.

Plog, S., F. Plog, and W. Wait. 1978. Decision making in modern surveys. In M. B. Schiffer (editor), Advances in archaeological method and theory, Volume 1, pp. 383-421. New York: Academic Press.

Polanyi, K. 1944. The great transformation. New York: Farrar and Rinehart.

Possehl, G. L. 2002. The Indus civilisation: A contemporary perspective. Walnut Creek: Alta Mira Press.

Pozorski, T., and S. Pozorski. 2018. Early complex society on the north and central Peruvian coast: New archaeological discoveries and new insights. Journal of Archaeological Research 26 (4): 353-386.

Ray, H. P. 2007. Colonial archaeology in South Asia: The legacy of sir Mortimer Wheeler. New Delhi: Oxford University Press.

Ray, H. P. and C. Sinopoli (eds.). 2004. Archaeology as history in early South Asia. New Delhi: Aryan Books.

Raychaudhuri, H. C. 1923. Political history of ancient India: From the accession of Parikshit to the extinction of the Gupta dynasty. Calcutta: University of Calcutta.

Renfrew, C., and B. Liu. 2018. The emergence of complex society in China: The case of Liangzhu. Antiquity 92 (364): 975-990.

Salles, Jean-François (editor). 2015. Mahasthan II, Fouilles du Rempart Est, Études Archéologiques. Archaeologies of the Indian Ocean, 10. Turnhout: Brepols.
Sawant, R. 2010. Review of archaeological investigations in the Protohistoric and historical archaeology of Vidarbha. Management of Environmental Quality 35 (2): 45-65.

Sawant, R. 2012. Historical archaeology of Vidarbha. New Delhi: Aryan Books and IGRMS.

Schiffer, M.B., A.P. Sullivan, and T.C. Klinger. 1978. The design of archaeological surveys. World Archaeology 10 (1): 1-28.

Sen, S. 2015. Settlements on the changing alluvial landscape in early medieval Varendri: Survey and excavations in Domile-Khairghuni in Dinajpur, Bangladesh. Management of Environmental Quality 40 (2): 33-64.

Shanks, M. and C. Tilley. 2016. Re-constructing archaeology: Theory and practice. London: Routledge.

Sharma, R. S. 1965. Indian Feudalism, c.300-1200. Calcutta: University of Calcutta.

Sharma, R. S. 1983. Material culture and social formations in ancient India. Delhi: MacMillan.

Shaw, J. 2017. A 'reflexive' multi-stage survey methodology for historical landscape research in Central India: Fieldwalking, local knowledge, and satellite imagery as archaeological site prospection and mapping tools in the Sanchi survey project. Current Science 113 (10): 1918-1933.

Shete, G. 2011-12. Exploration at Manjarkhed and surrounding area. Annual Report of the Deccan College 2011-12: 84.

Shinde, V. 2016. Current perspectives on the Harappan civilization. In $A$ companion to South Asia in the past, ed. G. Robbins Schug and S.R. Walimbe, 127-144. New York: Wiley.

Singh, U. 1994. Kings, Brahmanas, and temples in Orissa: An epigraphic study AD 300-1147. Delhi: Munshiram Manoharlal.

Singh, U. 2003. A history of ancient and early medieval India. New York: Pearson.

Singh, U. 2004. The discovery of ancient India. Delhi: Permanent Black.

Singh, U. 2009. A history of ancient and early medieval India: From the stone age to the 12th century. New Delhi: Pearson.

Singh, U. 2011. Rethinking early medieval India: A reader. New Delhi: Oxford University Press.

Smith, M.L. 2000. Systematic surface survey at the early historic site of Kaundinyapura, India. Management of Environmental Quality 25: 75-87.

Sontakke, V. G. 2014. Early Iron Age Archaeology of Upper Wainganga Valley with Special Reference to Gondiya District. Unpublished Ph.D. thesis. Pune: Deccan College.

Sontakke, V., S. Vaidya, S. Ganvir, and P. Joglekar. 2016. Excavation at Nagardhan, Nagpur District, Maharashtra 2015-2016. History Today 17: 43-51.

Stein, B. 1980. Peasant state and Society in Medieval South India. Oxford: Oxford University Press.

Stein, B. 1998. A history of India. Oxford: Wiley Blackwell.

Strandberg, G., E. Kjellström, A. Poska, S. Wagner, M.-J. Gaillard, A.-K. Trondman, A. Mauri, B. A. S. Davis, J. O. Kaplan, H. J. B. Birks, A. E. Bjune, R. Fyfe, , T. Giesecke, L. Kalnina, M. Kangur, W. O. van der Knaap, U. Kokfelt, P. Kuneš, M. Latalowa, L. Marquer, F. Mazier, A. B. Nielsen, B. Smith, H. Seppä, and S. Sugita. 2014. Regional climate model simulations for Europe at 6 and $0.2 \mathrm{k} \mathrm{BP}$ : Sensitivity to changes in anthropogenic deforestation. Climate of the Past 10 (2): 661-680.

Sullivan, A. P. (editor). 1998. Surface archaeology. Alberquerque: New Mexico University Press.

Sullivan, A.P., P.B. Mink, and P.M. Uphus. 2007. Archaeological survey design, units of observation, and the characterization of regional variability. American Antiquity 72 (2): 322-333.

Thakuria, T. 2009. Architectural variations of the Vidarbha megalithic burials, Maharashtra. In Abhijñann: Studies in south Asian archaeology and art history of Artefacts, ed. S.H. Jahan, 35-41. Oxford: Archaeopress. 
Thakuria, T., R.K. Mohanty, and P.P. Joglekar. 2015. Craft specialization and socio-economic behaviour of the megalithic people of Vidarbha, Maharashtra. In Megalithic traditions in ethnography and archaeology, ed. K.K. Basa, R.K. Mohanty, and S.B. Ota, 188203. New Delhi: Aryan Books.

Thapar, R. 1968. Interpretations of ancient Indian history. History and Theory 7 (3): 318-335.

Thapar, B. K. (editor). 1979a. Indian archaeology, 1973-74—A review. New Delhi: Government of India.

Thapar, B. K. (editor). 1979b. Indian archaeology, 1975-76-A review. New Delhi: Government of India.

Thapar, B. K. (editor). 1980a. Indian archaeology, 1976-77-A review. New Delhi: Government of India.

Thapar, B. K. (editor). 1980b. Indian archaeology, 1977-78-A review. New Delhi: Government of India.

Thapar, R., H. Mukhia, and B. Chandra. 1969. Communalism and the writing of Indian history. New Delhi: People's Publishing House.

Trigger, B. 2006. A history of archaeological thought. Cambridge: Cambridge University Press.
Vaidya, S. 2014. Emergence of Complex Society and Urbanisation During Early Iron Age and Early Historic Period in Wardha and Nagpur Districts of Vidarbha. Unpublished Ph.D. thesis. Pune: Deccan College.

Von Falkenhausen, L. 1993. On the historiographical orientation of Chinese archaeology. Antiquity 67 (257): 839-849.

Weiner S. 2010. Microarchaeology: Beyond the visible archaeological record. Cambridge: Cambridge University Press.

Wheeler, M. 1954. Archaeology from the earth. London: Oxford University Press.

Willey, G. 1953. Prehistoric settlement in the Virú Valley, Peru. Bureau of American ethnology, bulletin 155. Washington D.C.: Smithsonian Institution.

Wink, A. 2002. Al-hind, the making of the indo-Islamic world: Early medieval India and the expansion of Islam 7th-11th centuries. Leiden: Brill.

Wright, R. P. 2010. The ancient Indus: Urbanism, economy and society. Cambridge: Cambridge University Press.

Wurzer, G., K. Kowarik, and H. Reschreiter. 2015. Agent-based modeling and simulation in archaeology. New York: Springer. 